\title{
Gender Composition of the Boards of Directors of the Regional Federal Reserve Banks
}

Arantxa Jarque and Caroline Davis

$\mathrm{T}$ he Federal Reserve System is composed of the Board of Governors and twelve regional Federal Reserve Banks (the "Feds"). While the Board of Governors is a government agency, the Feds are semiprivate corporations with a governance structure similar to that of companies in the private sector, with the Feds' presidents serving as CEOs of their Banks. In particular, each Bank has a board of directors with oversight responsibilities similar to those of their private sector counterparts. Moreover, each board nominates the president of its Fed, indirectly influencing monetary policy. ${ }^{1}$ In this article, we present new data on these boards and analyze female representation among directors.

There is an explicit interest in increasing the diversity of policymakers at the Federal Reserve System. ${ }^{2}$ It is well-known that women and

Correspondence: Arantxa.Jarque@rich.frb.org. We thank the referees, Felix Ackon, Madeleine Ho, John Jones, and Zhu Wang, as well as the editor, John Weinberg, for very valuable comments. We also thank Lauren McCarey for help with the hand collection of gender data. The views expressed here are those of the authors and not necessarily those of the Federal Reserve Bank of Richmond or the Federal Reserve System.

${ }^{1}$ A subset of the directors of the main branch of each Fed nominates the new president of their Bank. These nominations need to be confirmed by the Board of Governors. In contrast, candidates for the Board of Governors are nominated by the president of the U.S. and need a U.S. Senate confirmation.

${ }^{2}$ During the search for presidents for the Federal Reserve Banks of San Francisco, Richmond, and Atlanta, Rep. Maxine Waters, together with other congressional Democrats, wrote letters to former Chair Janet Yellen and current Chair Jerome Powell calling for search processes that consider gender and racially, ethnically, and occupationally diverse candidates. See, also, Chair Powell's speech on diversity and inclusion in 
minorities have traditionally been underrepresented among governors of the Federal Reserve Board and among the presidents of the Feds. It has been argued that this lack of diversity may limit the representation of the interests of these groups. ${ }^{3}$ Moreover, there is some evidence that opinions among economists about policy differ across genders and that diversity changes group dynamics and decision-making. ${ }^{4}$ These concerns are also relevant for Fed officials beyond the presidents and governors, such as the members of the boards of directors of the Regional Banks, but the extent of female representation on these boards has not been, to our knowledge, documented systematically. ${ }^{5}$ This article seeks to fill this gap.

Using our hand-collected data, we analyze the gender composition of boards of directors of the twelve Regional Banks. There are nine head-office director seats per Bank. ${ }^{6}$ The first year women were hired as directors was 1977. That year there were five women out of the total 108 directors. As seen in Figure 1, the proportion of females has increased significantly since 1977 , reaching its peak of 31.5 percent (thirty-three women) in the last year of our sample, 2017. The average annual rate of increase during the whole period has been 0.5 percentage points. A simple extrapolation of this linear trend implies that it will take thirty-one more years to achieve an aggregate representation rate of 50 percent. If, instead, we wanted to achieve equal representation in only ten years, the annual increase in representation should be 1.85 percentage points.

In this article, we will analyze in detail the director data in order to perform an accounting exercise: we want to determine whether the increase in representation so far has been driven by changing selection ("hiring") practices, changes in retention, or both. This should help us identify the most effective ways to achieve higher female representation.

October 2018-available at https://www.federalreserve.gov/mediacenter/files/chairmanpowell-diversity-transcript-20181009.pdf.

${ }^{3}$ In a letter to Chair Yellen in May 2016, Sens. Conyers and Warren stated: "Given the critical linkage between monetary policy and the experiences of hardworking Americans, the importance of ensuring that such positions are filled by persons that reflect and represent the interests of our diverse country, cannot be understated. When the voices of women, African-Americans, Latinos, Asian Pacific Americans, and representatives of consumers and labor are excluded from key discussions, their interests are too often neglected." (Conyers and Warren 2016).

${ }^{4}$ See Bayer and Rouse (2016) for a summary of these studies.

${ }^{5}$ Since the passage of the Dodd-Frank Act in 2010, the regional Feds and the Board have published annually a report on the diversity of their workforce and their inclusion efforts. There is no information in those reports on the gender composition of the boards of directors. The Government Accountability Office (GAO) published a report in 2011 that analyzed similar data for the years 2007-10.

${ }^{6}$ There are also boards for each of the branches of the regional Feds, but these do not play the governance role that head-office boards do. 


\section{Figure 1 Representation of Female Board Members over Time}

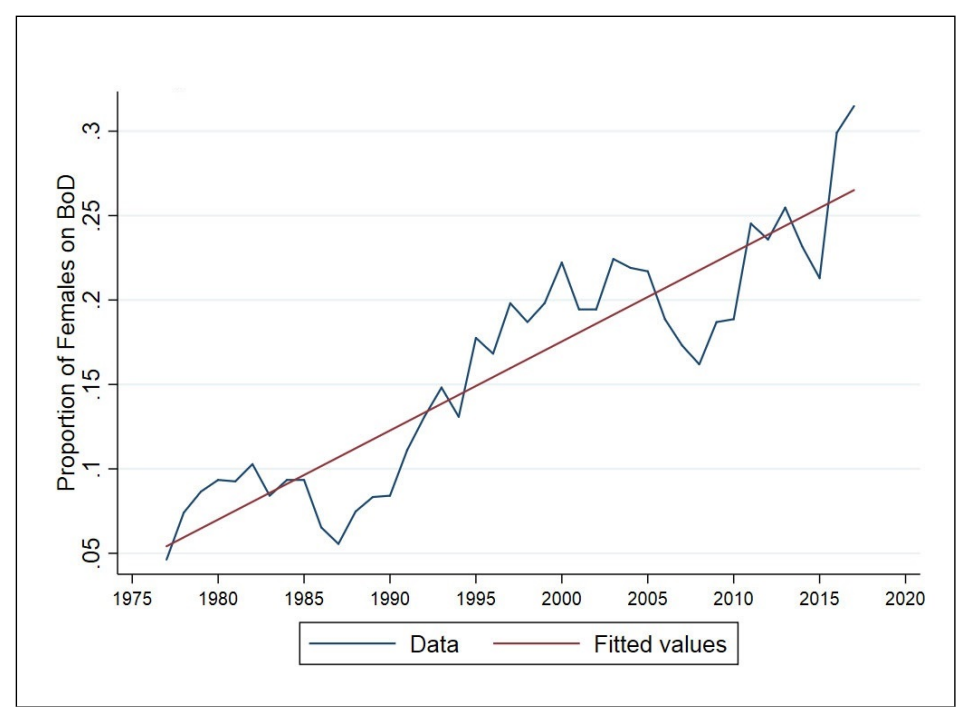

Note: Representation of females as a proportion of the 108 total director seats over time. We overlap the fitted trend of an OLS regression of representation on time (with an estimated coefficient of .005, i.e., half a percentage point increase every year).

Most directors in our sample are subject to maximum tenures of two three-year terms, with an extra year of service allowed for directors who were hired to finish someone else's term. Using detailed information at the director level on tenure and term completion to determine their eligibility to continue serving on the board, we construct quitting rates (i.e., the proportion of directors who leave their seats at a date when they could serve at least one more year). We find that directors do not quit very often in the middle of a term, and we find no important differences in quitting behavior across genders. We calculate a quitting rate for males of 7.6 percent, which is slightly higher than the average quit rate for females of 6.6 percent. There is no significant trend in quitting rates throughout our sample.

As a consequence of these low and gender-balanced quitting rates, the increase over time in the representation of women is due mostly to the natural work of term and tenure limits together with an increase in the hiring rate of females. The Fed's governance mandate of a maximum tenure of six years (or seven, for directors who came in 
as replacements) allows for relatively quick turnover of directors when compared with the private sector. We find that the female hiring rate has increased only modestly from 1977 to 2017, at about 6 percent per year on average. We find no significant differences in hiring rates of women, or in gender-specific quitting rates, across the twelve Banks.

We use the rates we recover from the data to calibrate a statistical model of the probability of having a woman occupy one of the 108 director seats. We use this model to perform predictions and counterfactuals. Under the quitting rates and the hiring trends we observe from 1977 to 2017, we forecast that in ten years from the end of the sample female representation will be 36.3 percent. An equal representation of females and males under the current parameters would occur thirty-one years out from 2017.

With the model in hand, we quantify the effect of a hypothetical change in hiring practices consisting of expanding the pool of candidates beyond CEOs, in the spirit of a recommendation from the Government Accountability Office (GAO) in 2011. To inform this exercise, we analyze the titles of directors hired (available starting in 1990) and interpret the representation of women across different "hiring pools" (CEOs versus lower-ranked executives) as the true rate of eligible women in them. Because we have no data on the offers made to potential candidates, nor their rate of acceptance, our interpretation cannot be validated and our counterfactual exercise should be interpreted with caution. We find that a shift in the hiring pool of directors (each Bank filling two positions from non-CEO executives instead of from the CEO hiring pool) may speed up female representation, reaching equal representation four years earlier than under current hiring policies. However, this is only the case if the growth rate in female hiring from lower ranks of corporations is close to that of the last twenty-five years. In the last ten years, the Feds seem to have been increasing the proportion of female hires within the CEO ranks faster than in hires from lower tiers of the corporate ladder. If that is more indicative of the expected representation of eligible women going forward, hiring from outside of the CEO pool would slow down the increase in female representation (reaching 50 percent one year later) and should probably be considered only under an explicit target of women.

Given our finding that changes in the female hiring rates have been the main driver of changes in female representation, we explore potential factors influencing the rate at which women are recruited to be directors of the Feds. Comparing female hires across female and male Fed presidents, we find no evidence that female presidents favor the hiring of - or are more successful in attracting - female directors. The board's gender imbalance, instead, seems to be an important driver of 
female hires: the probability of hiring at least one woman in a year with vacancies decreases with the number of women already serving on that board. In general, replacement is a common practice: when a female director leaves a board, the probability that a new female director will join the board the next year is 43.6 percent versus 21.5 percent if no female left. The proportion of new hires who are women in the year after a female director left the board is 23 percent, while only 12 percent of new hires are women when no female left.

The next section describes the data sources and the governance of the boards and lists the first female directors at each Fed. Section 2 discusses diversity in private sector boards to frame the discussion about Fed directors. In Section 3, we present a simple model of female representation as a function of hiring rates, quitting rates, and term restrictions, and we present data on each of these separately. Section 4 presents the results of our accounting exercise, where we use the rates recovered from the data to forecast female representation. We explore the hiring practices counterfactual in Section 5. Section 6 documents the effect of board diversity on hiring practices. Section 7 concludes.

\section{DATA DESCRIPTION AND INSTITUTIONAL DETAILS}

We use the hand-collected data in Jarque and McCrary (2017) that contains the name and dates of service of each director at the twelve Federal Reserve Banks. This information comes originally from the annual reports of the Federal Reserve System from 1914-2017, which are publicly available at the Board's website. We use the names of directors to determine their gender. We complement this data with public information online to determine the gender whenever the name is ambivalent. We also use information on Fed presidents' tenures and gender from Jarque and McCrary (2017). Once we determined the first year with a female director (1977), we limited our analysis to observations after that date.

Next we describe the rules governing the appointment of Bank directors, as well as their main responsibilities, compensation, and term limits. ${ }^{7}$ Although historical documentation of these rules and practices is not readily available, the data suggest that the current rules have been in place for most of our period of analysis (1977-2017).

\footnotetext{
${ }^{7}$ See "Roles and Responsibilities of Federal Reserve Directors" and other documents by Federal Reserve System Publications, available at https://www.federalreserve.gov /aboutthefed/directors/pdf/roles_responsibilities_FINALweb013013.pdf. See also the GAO report of 2011.
} 
There are nine head-office directors on each Bank's Board, with three directors in each of three classes, denoted A, B, and C:

- Class A directors represent the member banks in the district. They are chosen by member banks.

- Class B and C directors represent the public and "shall be elected... with due but not exclusive consideration to the interests of agriculture, commerce, industry, services, labor, and consumers." 8

- Class B directors may not be employees or directors of any Bank or any "financial affiliation company." They are chosen by member banks. ${ }^{9}$

- Class C directors are chosen by the Board of Governors.

The Board of Governors also chooses who, among the Class $\mathrm{C}$ directors, will serve as the chair and deputy chair of the board of directors, who are appointed annually. These appointments can be renewed for up to three years. Fed presidents, branch executives, and previous directors have strong influence on candidate proposals of all classes, and the final invitation is extended by the Fed president. Business and community contacts who are used by the Feds to gather information on the regional economy are often included in the candidate pools, though searches also extend to qualified candidates in the region who have no previous ties to the Feds. For bankers, state banking organizations were tapped in the past to propose candidates, though in recent years this

\footnotetext{
${ }^{8}$ See Federal Reserve Act, section 4, 12 U.S.C. section 302.

${ }^{9}$ From the Board of Governor's website: “[...] it is the Board's policy that a Class B director may not be an officer, director (including advisory director), or employee of a financial affiliation company, except in the limited circumstances described below.

For purposes of this policy, a financial affiliation company is defined as any bank, bank holding company, branch or agency of a foreign bank, Edge Act or agreement corporation, thrift institution, credit union, designated financial market utility ("DFMU"), systemically important financial institution ("SIFI") or subsidiary of any such company or entity. A financial affiliation company also includes any thrift holding company (also known as a savings and loan holding company) and any company that owns a bank or thrift institution (but is not a bank holding company or a thrift holding company), if, at the time of election, either (1) the total of all banks and thrifts controlled by the company constitutes 15 percent or more of the assets of the consolidated holding company or (2) the total assets of the banks and thrifts owned by the company exceed $\$ 10$ billion. Companies described in the previous sentence that fall below the 15 percent and $\$ 10$ billion thresholds are referred to herein as "15 percent test companies."

A Class B director who is affiliated with a 15 percent test company should be selected because of the individual's connection with the nondepository activities of the company and may not be an officer, director, or employee of any bank or thrift institution or a subsidiary of either. Reserve Banks are encouraged to have no more than one Class B director affiliated with a 15 percent test company on the Reserve Bank board at any one time."

Source: https://www.federalreserve.gov/aboutthefed/directors/PDF/eligibilityqualifications-rotation.pdf.
} 
Figure 2 Female Members over Time by Director Class

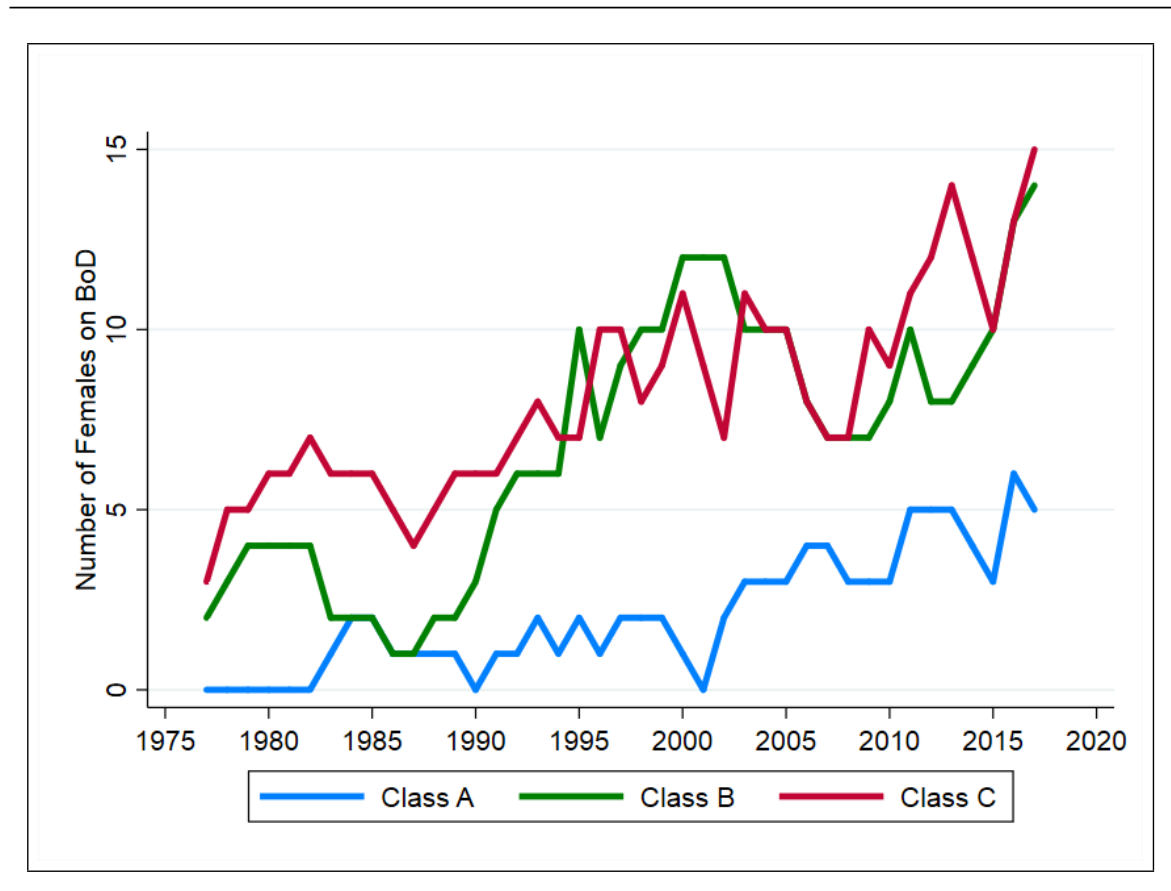

practice seems to have been discontinued to prevent potential conflicts of interest, as well as to minimize the potential signals that the acceptance or rejection of proposed candidates may give about solvency of the candidate's financial institution (which would have been acquired by the Feds through their confidential access to information via their supervision responsibilities).

Each of the three seats within Class A and Class B is chosen by a subgroup of member banks: all member banks are annually classified into large, medium, or small banks according to capital and surplus. Members in each of these three groups nominate and vote only on candidates who are to occupy the seat allocated to their group. The breakdown of female hires by director class is presented in Figure 2. A notable feature in this figure is that Class A directors, who come from the banking industry, have traditionally included fewer women overall.

Most Feds have at least one branch in addition to their head office. These branches have their own boards of directors, chosen partly by the directors of the head office and partly by the Board of Governors. In 
this study, we will restrict ourselves to analyzing the head-office boards of directors. ${ }^{10}$

The first woman to serve on a Board started her term at the FRB of Atlanta in 1977. A list of the first women hired for the Board of each Bank can be seen on Table 1. None of them were hired to a Class A seat. It is notable that it took eleven years for all the Feds to have had at least one woman on their Board, with five Banks hiring a woman in 1977 and Cleveland being a very late adopter. In contrast, Cleveland was the first Fed to have a female president (Karen Horn, who served as president from 1982-87). ${ }^{11}$ In the rest of the article we restrict our analysis to the years after the first woman was elected.

According to the Board of Governors' website, "Directors play an important role in the effective functioning of the Federal Reserve. All directors are expected to participate in the formulation of monetary policy and to act as a link between the System and the public. In addition, head-office directors are responsible for supervising the administration of their Reserve Bank's operations, overseeing the Reserve Bank's corporate governance function, and maintaining an effective system of internal auditing procedures and controls. Directors are not involved, however, in any matters related to banking supervision, including specific supervisory decisions."

Since the Banking Act of 1935 and until 2010, all nine directors were in charge of appointing new Fed presidents and first vice presidents. The Dodd-Frank Act of 2010 changed this, restricting Class A directors and Class B directors with ties to the financial industry from most of the appointment process. In particular, these directors cannot be on the search committee that identifies candidates, and they do not vote to approve a candidate.

Compensation of directors has been modest enough since 1936 to make the job only suitable for outside directors. (Chairs were fulltime employees for the first twenty years of the Fed, as discussed in McAfee [2004].) For illustration, directors are paid a daily fee ranging from $\$ 200$ to $\$ 300$ for attending directors' meetings, committee meetings, or other activities considered Bank business, including telephone conference calls. They are also paid an annual retainer of $\$ 2,000$ to $\$ 2,500$, or $\$ 5,000$ for the chair. There are established funds available at each Federal Reserve Bank designated to award directors who go beyond the scope of their regular responsibilities $(\$ 6,000$ available at

\footnotetext{
${ }^{10}$ A 2011 U.S. GAO report on Fed director diversity and governance reports statistics on gender diversity for the years 2006-10. While women represented 24 percent of new head-office directors, they represented 32 percent of the new directors of the branches. For details, see GAO (2011).

${ }^{11}$ We will explore ties between female presidents and board members in Section 6 .
} 
Table 1 First Female Appointment at each Regional Bank's Board with the First Year They Served

\begin{tabular}{|c|c|c|c|c|}
\hline Year & Bank & Class & Name & Employment \\
\hline 1977 & Atlanta & B & Jean McArthur Davis & $\begin{array}{l}\text { McArthur Dairy, Inc., } \\
\text { Miami, FL }\end{array}$ \\
\hline 1977 & Dallas & $\mathrm{C}$ & Margaret S. Wilson & $\begin{array}{l}\text { Scarbroughs Stores, } \\
\text { Austin, TX }\end{array}$ \\
\hline 1977 & Philadelphia & $\mathrm{C}$ & Jean A. Crockett & $\begin{array}{l}\text { U. of Pennsylvania } \\
\text { (Wharton), } \\
\text { Philadelphia, PA }\end{array}$ \\
\hline 1977 & San Francisco & $\mathrm{C}$ & Dorothy Wright Nelson & $\begin{array}{l}\text { U. of Southern Calif., } \\
\text { (Law Center), } \\
\text { Los Angeles, CA }\end{array}$ \\
\hline 1977 & St. Louis & B & Virginia M. Bailey & $\begin{array}{l}\text { Eldo Properties, } \\
\text { Little Rock, AR }\end{array}$ \\
\hline 1978 & Boston & B & Carol R. Goldberg & $\begin{array}{l}\text { The Stop \& Shop } \\
\text { Companies, Inc., } \\
\text { Boston, MA }\end{array}$ \\
\hline 1978 & Minneapolis & $\mathrm{C}$ & Sister Generose Gervais & $\begin{array}{l}\text { Saint Mary's Hospital, } \\
\text { Rochester, MN }\end{array}$ \\
\hline 1978 & New York & $\mathrm{C}$ & Gertrude G. Michelson & $\begin{array}{l}\text { R.H. Macy \& Co., Inc., } \\
\text { New York, NY }\end{array}$ \\
\hline 1979 & Chicago & $\mathrm{B}$ & Mary Garst & $\begin{array}{l}\text { Garst Company, } \\
\text { Coon Rapids, IA }\end{array}$ \\
\hline 1980 & Kansas City & $\mathrm{C}$ & Doris M. Drury & $\begin{array}{l}\text { U. of Denver, } \\
\text { Englewood, CO }\end{array}$ \\
\hline 1985 & Richmond & $\mathrm{C}$ & Hanne Merriman & $\begin{array}{l}\text { Retail Business } \\
\text { Consultant, } \\
\text { Washington, D.C. }\end{array}$ \\
\hline 1988 & Cleveland & $\mathrm{C}$ & Verna K. Gibson & $\begin{array}{l}\text { Outlook Consulting } \\
\text { International, Inc., } \\
\text { Columbus, OH }\end{array}$ \\
\hline
\end{tabular}

each Bank for all head-office directors), but the use of these funds has historically been very rare. Moreover, these compensation figures have been unchanged since 1981.

Directors are appointed to serve three-year terms, although they can - and sometimes do - quit at the end of the calendar year even if they have not completed their terms. Each of the three seats within each class has a three-year term assigned to it, in a staggered fashion; if a director leaves before his or her seat's term has expired, the new director completes the term of the outgoing one. This means that within each class, at the beginning of each year, one seat has a full term of three years remaining ("slot 1"), one has two years of the term remaining ("slot 2"), and one has only one year left ("slot 3").

Although only Class $\mathrm{C}$ directors have explicit tenure limits, Banks are encouraged by the Board to follow the same rules for all classes: 
directors cannot be reappointed for more than two full three-year terms and cannot be reappointed for a term if by the end of the term they would have served for more than seven years. Exceptions are allowed with waivers from the Board of Governors. In our sample all classes seem to be working under these maximum tenure rules. ${ }^{12,13}$ The maximum tenures of eight or nine years observed in our sample constitute exceptions to the rule, and anecdotal evidence suggests that these requests to keep directors in their seats for longer had the objective of maintaining continuity in instances when otherwise there would be particularly high turnover of directors.

Data, confirmed by anecdotal evidence, suggest that some of the regional Banks operate on a different term structure for Class A directors: they do not offer a second term to the same person, presumably to increase turnover and maximize representation of member banks in the district. We will discuss these practices in Section 3.

The Fed governance rules for maximum tenure of directors are stricter than those for most boards of private sector companies. In a survey of practices of S\&P 500 companies, PwC found that in 2017, director term limits were only used by 5 percent of S\&P 500 boards, and most are set at fifteen years or more. According to the survey, 73 percent of boards had adopted mandatory retirement ages, but for 96 percent of these boards, the retirement age was seventy-two or higher, with this age limit increasing in the last decade. ${ }^{14}$ This is thought to represent the reluctance of boards to replace currently serving directors who are useful to the company. The average tenure of independent S\&P 500 directors was 8.2 years in 2017, while for Fed directors it was, on average, 4.84 years from 1977 to 2017. Institutional investors such as Blackrock or the California Public Employees Retirement System have pointed out that longer tenures have the obvious advantage that comes with experience but that they may be a problem if viewpoints do not evolve over time and become stale, and they may compromise independence ( $\mathrm{PwC} 2018 \mathrm{a})$.

For the purpose of putting the statistics we provide in this study into perspective, in the next section we present some information on the representation of females on the boards of private sector compa-

\footnotetext{
${ }^{12}$ We end the sample in 2011 for replacement directors or 2012 for nonreplacements when constructing these statistics since we do not observe complete histories for the directors starting after these years.

${ }^{13}$ Based on tenure data, these seem to be the governing rules for all classes starting in the mid-1960s. In earlier years, some directors were completing upward of twenty years of service.

${ }^{14}$ We are not aware of retirement age limits for Fed directors, and we do not have age information for the directors in our dataset.
} 
nies. This comparison should be taken with caution: since the Feds have a markedly different objective and way of operating than most private sector companies, the role of Fed directors is somewhat different from those of private sector company boards. For example, each individual Fed has limited discretion over their own budget, and hence directors are not expected to monitor it. However, many oversight responsibilities, such as auditing financial statements, approving compensation of executives, and contributing to succession planning, are similar to those in the private sector, and they constitute an important part of the Fed's directors' duties. Hence, the pool from which Fed directors are typically hired is similar to that of hires of private sector boards: CEOs and other high-ranking executives. The gender composition of this hiring pool will naturally influence female representation among directors. It should be noted, however, that for an executive to be eligible as a Fed director, he or she needs to satisfy numerous restrictions, and this restricts the hiring pool further. Directors need to be chosen in equal representation from member banks (Class A), the broader economy (Class B), and certain sectors that represent the general public (Class C). Different classes face different requirements; for example, class A directors should be chosen over time so that they represent all states within a district. Other requirements applying to all directors are a two-year residency in the district, the expectation of experience serving on other boards, active employment rather than retirement, and a record of community service. There are also disqualifying situations, such as political affiliations or receiving appointments or funding from elected officials and parties. Finally, another important difference between director positions in the private sector and the Fed is that compensation for Fed directors is nominal. Serving on the Board is mainly considered public service, with its main tangible benefit arguably coming from reputation and networking opportunities.

\section{DIVERSITY IN PUBLICLY HELD COMPANY BOARDS AND IN THE FINANCIAL INDUSTRY}

Diversity within the boards of publicly held companies has been an issue of interest in recent years. Vinnicombe (2008) provides an international perspective both on representation and on accessibility issues. A $\mathrm{PwC}$ report on survey results stressed the importance of diversity by providing anecdotes of institutional investors voting against directors in companies that did not have enough diversity - or that did not address the problem adequately according to the investors $(\mathrm{PwC}$ 
Table 2 Women as a Percentage of Board Seats for Fortune 100 Companies, Fortune 500 Companies, and the Twelve Federal Reserve Banks

\begin{tabular}{lllll}
\hline & 2004 & 2010 & 2012 & 2016 \\
\hline FRB & 21.9 & 18.7 & 24.5 & 29.9 \\
Fortune 100 & 16.9 & 18.0 & 19.8 & 22.9 \\
Fortune 500 & n/a & 15.7 & 16.5 & 20.2 \\
\hline
\end{tabular}

2018b). ${ }^{15}$ Moreover, the report documented divergence of opinions between male and female directors regarding issues of corporate culture, talent management, social concerns, and the diversity of the board itself.

Table 2 presents data from a 2016 report by Deloitte, another consulting firm, that pertains to two groups of companies: Fortune 100 and Fortune 500 companies. ${ }^{16}$ The report presents data in four nonconsecutive years in the 2004-16 period and for 492 companies, for a total of 5,440 board seats. In each year there is a greater percentage of women on Fortune 100 boards than on Fortune 500 boards. We report in the table, for comparison, the corresponding proportion of women on the boards at the twelve Reserve Banks for the years in their sample. The representation at the Fed surpasses that of the Fortune companies.

Given that the pool of potential directors draws mostly from senior management positions, representation of women in those positions is a necessary condition for having a diverse pool of directors. In particular for the Fed positions, representation in banking is key: the lower rate of female hiring in Class A could be due in part to a lower availability of female CEOs in banking. According to a recent report by the GAO, in the financial services industry representation of women remained largely unchanged between 2007 and 2015, around 48 percent among first- and mid-level managers and around 29 percent among senior-level managers (GAO 2017). The study also explored the pipeline for those management positions, both external and internal, to companies. The external pool includes those with undergraduate or graduate degrees, such as a master's of business administration; in 2015, about 60 percent of this pool were women. The internal talent pool for potential

\footnotetext{
${ }^{15}$ The 2018 annual PwC survey of U.S. corporate directors included 714 directors from a cross-section of companies from over a dozen industries, of which 76 percent have annual revenues of more than $\$ 1$ billion. Eighty-one percent of the respondents were men, and 19 percent were women ( $\mathrm{PwC} 2018 \mathrm{~b})$.

${ }^{16}$ These are, respectively, the top 100 and 500 publicly held U.S. companies by revenue, in a given fiscal year, according to Fortune magazine.
} 

Table 3 Proportion of Females on the Boards of the Feds Compared with the Proportion of Females among Senior Executives

\begin{tabular}{llll}
\hline \hline & & & \\
& 2007 & 2008 & 2009 \\
\hline Directors of regional Feds & 17.4 & 16.4 & 17.7 \\
All-industry senior executives & 28.6 & 29.0 & 28.3 \\
$\quad$ - in banking & 30.9 & 30.0 & 29.0 \\
- in industries other than banking & 28.5 & 28.9 & 28.3 \\
\hline
\end{tabular}

Note: According to EEOC statistics. Source: GAO (2011).

managers in financial services includes those already in professional positions; in 2015, just over 51 percent were held by women.

More specifically for the banking sector, Haslett and Dholakia (2018) report that since 2013 the percentage of women CEOs among public banks and thrifts has increased only 0.8 percentage points, from 3.5 percent to 4.3 percent in 2017. However, a 2011 GAO study comparing female representation in Fed directors and private companies did not find a significantly lower availability of qualified candidates in banking compared with other sectors. The GAO's analysis of Equal Employment Opportunity Commission (EEOC) data found that diversity among senior executives is generally limited, but Fed boards had less female representation than was found in the senior management of private sector companies: as reflected in Table 3, the representation of women was about 10 percentage points lower among the Fed boards than in the EEOC data. ${ }^{17}$ The report found that the Feds generally limit their director search efforts to senior executives. While some Reserve Banks recruit more broadly, the GAO recommended that the Federal Reserve Board encourage all Reserve Banks to consider ways to help enhance the economic and demographic diversity of perspectives on the boards, including by broadening their potential candidate pool.

\footnotetext{
${ }^{17}$ Data reported in GAO (2011). For their benchmarking to industry standards, they analyzed EEOC's EEO-1 data for employers with 100 or more employees from 2007 through 2009. The EEO-1 data provide information on racial/ethnic and gender representation for various occupations within a broad range of industries. We used the EEO-1 "executive and senior level officials and managers" job category as the basis for our analysis because this is the category of employees from which Reserve Banks would most likely recruit directors. EEOC defines the job category of executive and senior-level officials and managers as individuals residing in the highest levels of organizations who plan, direct, and formulate policies and provide overall direction for the development and delivery of products and services.
} 
We will consider this recommendation when exploring counterfactual policies in Section 5 .

The findings in the corporate governance literature about the effect of female directors in the private sector provide a useful background for our study, even if directors at the Feds have slightly different responsibilities and objectives than those in private companies. ${ }^{18}$ Using a panel of approximately 300 unregulated Fortune 1000 firms in the '90s, Farrell and Hersch (2005) find that the increase in representation during this period from 5.6 percent in 1990 to 12.26 percent in 1999 is most likely driven by internal or external calls for diversity rather than by the expectation that women bring more value to the firms. We check for this type of hiring dynamic in our data in Section 6 and find a similar pattern: the probability of hiring a new female director increases significantly when a current female director leaves and is negatively affected by the number of women already on the board. There is some evidence within the banking sector that questions this hiring practice: using data on U.S. bank holding companies, Owen and Temesvary (2018) document a nonlinear relationship between gender diversity on boards and various measures of bank performance: adding more women to the board improves overall performance only if there is already at least one woman on the board. Adams and Ferreira (2009) find that female directors are better monitors: they have better attendance, participate in more committees, and the CEOs of their companies have more variable pay. However, they only find a positive influence of women on firm performance for firms that have worse governance to start with.

A few papers have studied the effect of the minimum quota of 40 percent female representation introduced in Norway in 2003. Ahern and Dittmar (2012) find that the introduction of the measure had a negative effect on firm value. It led to younger and less experienced boards, increases in leverage and acquisitions, and deterioration in operating performance. However, Bertrand et al. (2019) present evidence from the same Norwegian episode that women appointed as directors were better qualified than their female predecessors and benefitted in terms of wage from this policy, while the gains for similarly qualified females who were not appointed as directors were limited. Finally, Matsa and Miller (2013) compare affected firms with other Nordic companies, public and private, that are unaffected by the rule and find that affected firms undertake fewer workforce reductions than comparison firms, increasing relative labor costs and employment levels and reducing short-term profits.

\footnotetext{
${ }^{18}$ Recent papers studying the effect of female managers and CEOs on private sector firm performance and wages include Flabbi et al. (2018) and Kunze and Miller (2017).
} 


\section{THE DETERMINANTS OF FEMALE REPRESENTATION}

The proportion of females on Fed boards of directors (what we refer to as the rate of "representation") has been increasing fairly steadily since 1977, as seen in Figure 1. Representation depends on quitting rates, hiring rates, and maximum-tenure practices. The following simple model of the representation of females in one single slot illustrates this point and provides a framework for our measurements later in the paper.

\section{A simple model of representation for one seat on the board}

At any point in time $(t)$ a given seat on a board may be occupied by a female or a male director. Assume that there are no term limits, so that both the slot occupied or the tenure of the director are irrelevant for transitions. Simply, every time a director quits, the new director hired is a female with probability $\pi$. Assume as well that females quit in a given period with a probability of $q$, while males quit with a probability of $q+\Delta$, where $\Delta$ can be positive or negative. The probability that a female is occupying that seat in period $t+1$, denoted by $\gamma_{t+1}$, together with the corresponding probability for a male, $1-\gamma_{t+1}$, is given by the following equation:

$$
\left[\gamma_{t+1}, 1-\gamma_{t+1}\right]=\left[\gamma_{t}, 1-\gamma_{t}\right] \Pi,
$$

where $\Pi$ is the transition matrix:

$$
\Pi=\left[\begin{array}{cc}
1-\operatorname{Pr}(\text { male } \mid \text { female }) & \operatorname{Pr}(\text { male } \mid \text { female }) \\
\operatorname{Pr}(\text { female } \mid \text { male }) & 1-\operatorname{Pr}(\text { female } \mid \text { male })
\end{array}\right] .
$$

As in any model of transitions, the key parameters are the "switching" probabilities; the comparison of $\operatorname{Pr}$ (male|female) and $\operatorname{Pr}$ (female $\mid$ male) (the probability that a male occupies a seat next period, conditional on it being occupied by a female today, and vice versa) will be informative about long-term female representation, as we show next. In terms of the parameters of our model, we have:

$$
\Pi=\left[\begin{array}{cc}
(1-q)+q \pi & q(1-\pi) \\
(q+\Delta) \pi & (q+\Delta)(1-\pi)+(1-q-\Delta)
\end{array}\right] .
$$

It can be shown (see the Appendix) that $n$ periods ahead, the probability of having a female director in that slot, $\gamma_{t+n}$, given an initial representation of $\gamma_{0}$, is equal to

$$
\gamma_{t+n}\left(\gamma_{0}\right)=(1-q-\pi \Delta)^{n} \gamma_{0}+\left[1-(1-q-\pi \Delta)^{n}\right] \frac{\pi q+\pi \Delta}{q+\pi \Delta} .
$$


The term $(1-q-\pi \Delta)$ captures the combined rate at which the gender of the seat is not switching (1 minus the sum of the switching rate of a seat occupied by a male and the switching rate of a seat occupied by a female). When $n$ is small, the term $(1-q-\pi \Delta)^{n}$ is closer to 1 and representation is closer to the initial representation, $\gamma_{0}$. When $n$ is very large, the term $(1-q-\pi \Delta)^{n}$ is small and representation is closer to $\frac{\pi q+\pi \Delta}{q+\pi \Delta}$; this is the probability of having a female occupy the seat in the long term. In other words, we can characterize period- $n$ representation, for a given initial condition, as a weighted average of initial conditions and the long-term distribution. As $n$ grows, the weight of the initial conditions goes to zero. Note that if the quitting probability is the same for females and for males (i.e., $\Delta=0$ ), representation after $n$ periods simplifies to:

$$
\gamma_{t+n}\left(\gamma_{0}\right)=(1-q)^{n} \gamma_{0}+\left[1-(1-q)^{n}\right] \pi .
$$

Here, the combined nonswitching rate is simply $1-q$, and the longterm representation of females is equal to their hiring rate $\pi$. If $\Delta$ is positive (negative), it decreases (increases) the combined nonswitching rate by $\pi \Delta$ (since males quit $\Delta$ more than females, and the hire to replace them will be female - a switch - with probability $\pi$ ). A positive (negative) value of $\Delta$ also pushes the long-term female representation rate upward (downward):

$$
\frac{\partial\left(\frac{\pi q+\pi \Delta}{q+\pi \Delta}\right)}{\partial \Delta}>0
$$

that is, for a given female hiring rate of $\pi$, long-term representation of women is higher if females quit less often than men.

In the case of the Fed boards, term limits imply that long-term representation will not be determined by these simple expressions. In particular, tenure limits imply that after a maximum of seven years, there will be a new hire, even without observing a quit by the incumbent. We will document the way in which term completion and tenure affect quitting rates, so we can understand how allowing replacement directors to serve a second term can affect retention and overall representation.

Once we incorporate in our model the formal tenure and term restrictions, at any point in time the transition probabilities governing each of the 108 slots in the Fed will vary. As a result, an analytical solution is unavailable, and we must rely on numerical models to measure the aggregate transitions. To get the parameters that guide these transitions, we analyze separately quitting rates, hiring rates, and maximum-tenure practices in the rest of this section. We present a summary of our findings in Table 4 . We report the average proportion 
Table 4 Average over Time of the Main Statistics in our Sample

\begin{tabular}{llllll}
\hline \hline & & & & \\
& & & & \\
& & All & A & B & C \\
\hline Female representation $(\gamma)(\%)$ & $1977-2017$ & 16.0 & 5.8 & 19.3 & 22.8 \\
& Last 10 yrs & 23.3 & 11.7 & 26.6 & 31.7 \\
\hline Yearly increase in representation $(\%)$ & $1977-2017$ & 0.53 & 0.34 & 0.69 & 0.55 \\
& Last 10 yrs & 1.37 & 0.60 & 1.75 & 1.74 \\
\hline Proportion of females in new hires & $1977-2017$ & 16.6 & 7.3 & 21.3 & 23.6 \\
$(\pi)(\%)$ & Last 10 yrs & 26.8 & 15.9 & 28.5 & 38.0 \\
\hline Yearly increase in $\pi(g)(p . p)$. & $1977-2017$ & 0.57 & 0.43 & 0.65 & 0.62 \\
& Last 10 yrs & 1.98 & 0.44 & 4.05 & 0.25 \\
\hline Female quitting rate $(q)(\%)$ & $1977-2017$ & 6.6 & 4.4 & 6.9 & 7.0 \\
(incl. only directors with tenure $\leq 6)$ & Last 10 yrs & 8.0 & 10.0 & 8.1 & 6.3 \\
\hline Excess male quitting rate $(\Delta)(\%)$ & $1977-2017$ & 1.0 & 1.8 & 0.8 & 2.3 \\
(incl. only directors with tenure $\leq 6)$ & Last 10 yrs & 0.8 & -3.0 & 0.6 & 4.9 \\
\hline
\end{tabular}

of board seats occupied by women $(\gamma)$ and its growth rate, the proportion of new hires who are women $(\pi)$ and its growth rate $(g)$, and the "true" quitting rate $(q)$, which corrects for exits due to reaching maximum tenure. We report these rates for the 1977-2017 overall sample period, as well for the last ten years (2008-17). ${ }^{19}$

A significant increase in the hiring rate, $\pi$, can be seen by comparing the rate for the entire sample period (16.6 percent) with that of the last 10 years (26.8 percent). This trend is captured by the growth in the hiring rate, $g$, which is 0.57 percentage points over the entire sample but has been 1.98 percentage points in the last ten years. Class A seats tend to have fewer female hires per year than Class B and Class C seats, and when we check our data, we see that Class A accounts for a larger number of hires each year. Figure 3 shows a steady increase of the female hiring rate over the sample period. In contrast, the number of directors hired each year stays somewhat constant over time, with an average of 22.4 directors per year.

When looking at average quitting rates, we note that for the entire sample, males quit a bit more often than females (1 percentage point more), although in the last ten years this has decreased slightly, to be

\footnotetext{
${ }^{19}$ We check for differences in hiring and quitting rates across the twelve regional Banks. There are no stark differences across Banks in representation, hiring, or quitting rates. Statistics by Bank are available upon request.
} 
Figure 3 Females as a Proportion of New Hires

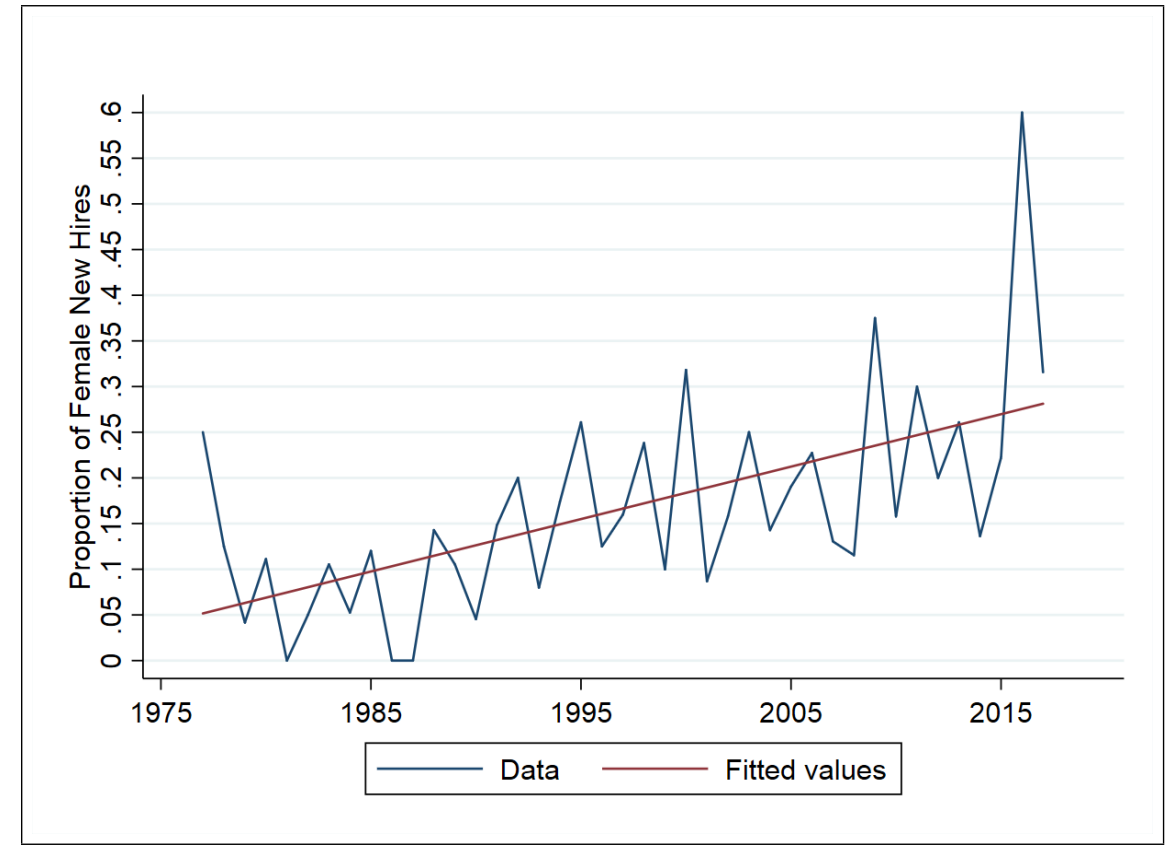

0.8 percentage point more than females. A quick back-of-the-envelope calculation using the average rates for the last ten years in our simple model can help us understand the edge over the hiring rate that comes from the difference in quitting rates between females and males. We plug the parameters from the last ten years into equation 1, using as an initial condition a male in the seat at time $0\left(\gamma_{0}=0\right)$. We find that by the tenth year, the probability of having a female in that seat is $\gamma_{10}(0)=0.17$. This probability goes up to $\gamma_{10}(0)=0.19$ if we cut the female quitting rate in half (4 percent) but keep the male rate at the 8.8 percent found in the data. If instead we consider a seat initially occupied by a female $\left(\gamma_{0}=1\right)$, this probability is $\gamma_{10}(1)=0.59$ when $q$ and $\Delta$ take their true sample values, and it becomes $\gamma_{10}(1)=0.77$ when we artificially set females quitting rates to 4 percent and keep male ones at 8.8. The difference in the effect of this policy across the two examples is due to $\pi$ being set to 26.8 percent, the average over the last 10 years. Because it is significantly lower than 50 percent, the initial gender of the director is very decisive. Recall that $\pi$ has been growing over time, at about 2 percentage points per year during the 
Table 5 Classification of Hiring Model by Percentage of Class A Directors who Start a Second Term (T2)

\begin{tabular}{lcc}
\hline Bank & $\begin{array}{c}\text { T2 Starting } \\
\text { Rate }(\%)\end{array}$ & $\begin{array}{c}\text { Hiring } \\
\text { Model }\end{array}$ \\
\hline Atlanta & 89.5 & 2 \\
Chicago & 85.0 & 2 \\
Dallas & 85.0 & 2 \\
Kansas City & 76.2 & 2 \\
St. Louis & 76.2 & 2 \\
New York, 1993 and after & 75.0 & 2 \\
San Francisco & 64.0 & 2 \\
Cleveland & 62.5 & 2 \\
Boston & 13.3 & 1 \\
Philadelphia & 12.1 & 1 \\
Minneapolis & 5.4 & 1 \\
New York, before 1993 & 0.0 & 1 \\
Richmond & 0.0 & 1 \\
\hline
\end{tabular}

last ten years. When we simulate the full model with variable quitting rates, we will also consider the growth in hiring rates over time.

\section{Exits and quits}

Using our data to learn about the relevant quitting rates in our statistical model takes some work. In order to correctly estimate the probability that a director leaves their position before his or her maximum tenure is reached (what we call a "true quit"), we need to understand the term structures. Formally, the tenure rules put forth by the Board of Governors for Class C directors allow them to serve for two complete terms. Although the Board has recently encouraged the Feds to follow these rules for all classes, we find both empirical and anecdotal evidence that a number of the Feds traditionally have not offered a full second term to their Class A directors. We classify Banks as "Hiring Model 1" (HM1) if they only offer one term and "Hiring Model 2" (HM2) if they offer two. To sort the Banks into these two models based on their treatment of Class A directors, we look at the proportion of new hires in a given year who eventually start a second term. Table 5 displays this rate for each Bank. We assign the hiring model based on the clear two groups defined by the stark differences in the rates: we classify the four Banks with fewer than 14 percent of directors starting a second term (Boston, Minneapolis, Philadelphia, and Richmond) as HM1. The rest all have rates above 62 percent, and we classify them as HM2. 
Figure 4 Average Quitting Rates over Time

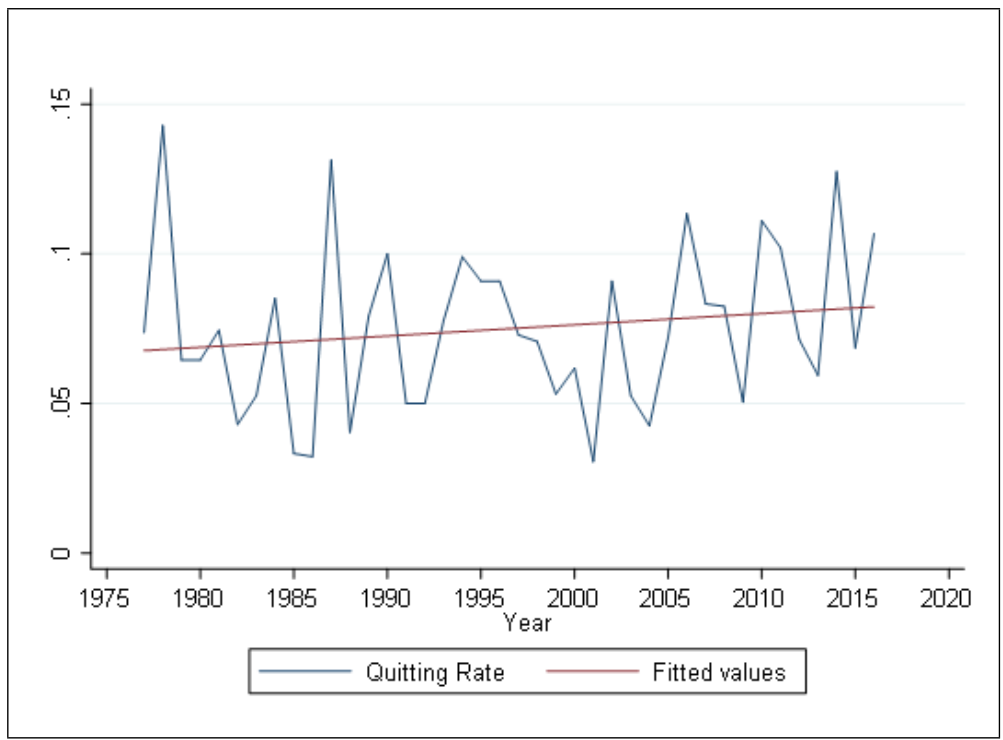

For New York, we see that before 1993 no Class A hires ever started a second term. Instead, after 1993 we see that 75 percent of directors start a second term, hence making this Bank's term structure similar to other Banks that we have classified as hiring according to HM2. Because for no other Bank in HM2 do we see such a long stretch of time with no second terms started, we decide to classify New York as two different models: before 1993, New York is hiring according to HM1, and after 1993, it is hiring according to HM2.

With that classification of Banks into HM1 or HM2, we can construct a measure of "true" quits (i.e., an instance when we observe a director leaving even though the corresponding tenure restrictions given the hiring model that applies to this director would allow him or her to serve at least one more year). Figure 4 plots the evolution of the average quitting rate over time. When the quitting rate is regressed on year, the coefficient is .00038 , implying that the quitting rate increases about 0.04 percentage points on average.

Table 6 presents the weighted (by numbers of males and females in each class) average quitting rates across classes, for the whole period and for the last ten years. Because there are fewer observations when we restrict the sample to the last ten years, we exclude from the table 
Table 6 Quitting Rates by Tenure of Female and Male Directors

\begin{tabular}{|c|c|c|c|c|}
\hline \multirow[b]{2}{*}{ Tenure } & \multicolumn{2}{|c|}{$\begin{array}{l}1977- \\
2017\end{array}$} & \multicolumn{2}{|c|}{$\begin{array}{c}\text { Last } 10 \\
\text { years }\end{array}$} \\
\hline & $q$ & $\Delta$ & $q$ & $\Delta$ \\
\hline 1 & .03 & .01 & .03 & .01 \\
\hline 2 & .03 & -.01 & .04 & .01 \\
\hline 3 & .23 & -.02 & .24 & -.10 \\
\hline 4 & .02 & .04 & 0 & .06 \\
\hline 5 & .08 & -.02 & .07 & .04 \\
\hline Average & 6.6 & 1.0 & 8.0 & .8 \\
\hline
\end{tabular}

Note: Statistics for sample of nonreplacement directors who started in 2012 or earlier (i.e., directors who could have completed at least two full terms by end of 2017).

the replacement directors. ${ }^{20}$ This means that for any given tenure, the director can only be serving in one particular slot (which determines years left in current term); for example, a nonreplacement director can only have a tenure of four years when he or she is in slot 1 (in their second term of service). Over all classes, quits after three years are a lot more common, about 20 percent, while for other tenures the quitting rate ranges from 2 to 8 percent.

As illustrated in the simple model presented earlier, a difference in the quitting rates across genders can have important implications in the long-term representation of females. Figure 11 in the Appendix presents the complete set of quitting rates by gender, class, slot, and tenure that we will use in our numerical examples. We find that most of the measured values of $\Delta$ are small but positive (i.e., males quit at slightly higher rates than females), but negative values are not uncommon. One notable change in recent years is the increase in absolute terms of the negative $\Delta$ for directors occupying a slot 3 with a tenure of three years. This means that while females were only quitting slightly more often than men in a $(3,3)$ position in the past, in the last ten years females have been quitting twice as often as men.

These patterns are the flip side of tenure (total number of consecutive years a director has served) and term completion. Over the entire

${ }^{20}$ The corresponding statistics for replacement directors are included in the appendix, together with the statistics for the last ten years. 
sample, 1977-2017, average tenure is $4.82 .{ }^{21}$ The average tenure for men is 4.76 years, while women have a tenure 0.43 years longer; this difference is significant at the 5 percent level. Over 92.5 percent of all directors complete their first term, with no significant difference by gender. ${ }^{22}$

\section{IMPLICATIONS OF HIRING AND QUITTING RATES FOR LONG-TERM REPRESENTATION OF FEMALES}

We saw in our simple model of transitions that, for a constant hiring rate over time of $\pi$, if quitting rates are the same across genders (i.e., $\Delta=0$ ), then the long-term female representation is equal to the hiring rate $\pi$. On the Fed boards, because complete refreshment happens in at most six periods (due to the maximum tenure rules), after period seven the expected representation would be equal to the prevalent hiring rate $\pi$, regardless of the value of the quitting rates. This means increases in the hiring rate can be very effective in increasing female representation in less than a decade. To project the potential effects of the increasing trend in female hiring we observe in the data, in this section we use a statistical model of the comings and goings of directors according to actual tenure rules to predict (i) female representation in ten years, and (ii) the years it will take to achieve 50 percent representation. We parametrize our baseline model (P1) with the numbers we recovered from the data and then consider a counterfactual exercise (P2) in Section 5.

For all of our exercises, we treat the increase in hiring rates observed in the data as sustainable for extended periods. ${ }^{23}$ We are assuming that whatever the explicit efforts to increase female representation have been, they can continue and will manage to increase hiring rates for as long as necessary at the same annual growth rate. We use the trend in hiring rates that we recovered from the data, $g$, starting from the true hiring rate at the end of our sample, $\pi_{2017}$, to produce a forecast

\footnotetext{
${ }^{21}$ Since most of the observed tenures comply with the recommended term structure for Class C directors that is currently in place, we report statistics about tenure including the few "outliers" where directors served more than seven years (one director served nine, and ten directors served eight years). However, we drop from our sample a few of the directors (twenty-nine) who change classes. Because total consecutive tenure is what matters for limits on service under the current rules, we would be misinterpreting the starting and end dates for these directors within a class.

${ }^{22}$ Details on tenure and term completion by gender and class are available upon request.

${ }^{23}$ We discuss potential determinants of the female hiring rate in Section 6 .
} 
Figure 5 Representation Projections and Paths

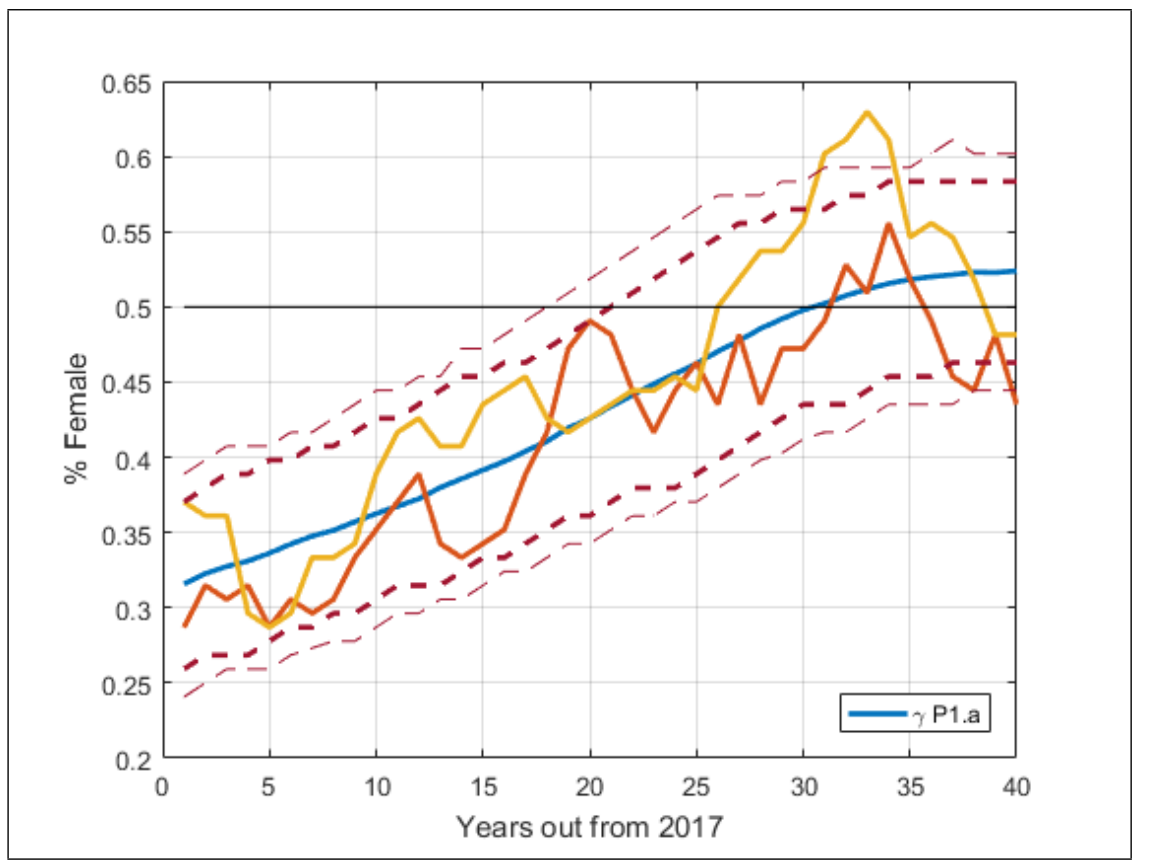

Note: Projected female representation. The blue line depicts the average, and dotted lines indicate the ninetieth and ninety-fifth percentile confidence bands. The light yellow and orange lines represent two of the 1,500 paths of realizations used to calculate the mean.

of hiring rates:

$$
\pi_{2017+t}=\left\{\begin{array}{ll}
\pi_{2017}+g t & \text { if } \gamma_{k}<50 \text { for all } k<t \\
50 & \text { otherwise }
\end{array} ;\right.
$$

that is, we assume the hiring rate increases at a growth rate $g$ until representation reaches 50 percent for the first time, then it settles to 50 percent. As reported in Table 4, hiring rates increased over our sample period about half a percentage point per year $(g=0.57)$. Table 4 also shows that in the last ten years, the growth in the female hiring rate has been much faster ( $g=1.98$ percentage points); to consider the implications of maintaining this higher growth rate going forward, we conduct our forecasts using data for the whole sample (P1.a) and only for the last ten years (P1.b). For all the exercises we use the quitting rates by class, slot, and tenure found in the data during the subsample considered in the parametrization. For all parametrizations we start 
Table 7 Numerical Results: Female Representation after Ten Years, and Years to Equal Representation

\begin{tabular}{lllll}
\hline \hline \multirow{2}{*}{ Specification } & & & & \multicolumn{2}{c}{ Years to } \\
P1. Baseline & a. whole sample & 0.5 & 36.3 & 31 \\
& b. 2008-2017 & 1.98 & 44.4 & 13 \\
\hline
\end{tabular}

Common parameters:

$\pi_{2017}=31.1, \quad \gamma_{2017}=31.5$

Note: Hats denote values found in each experiment, while no hats denote the value recovered from the data.

the simulation with the female representation across directors' slots that was observed in the data at the end of the sample $\left(\gamma_{2017}=31.5\right)$. We set the initial period hiring rate equal to the average rate in the data: $\pi_{2017}=31.1$ percent. We assume all Banks are hiring according to HM2, since that is the recommendation of the Board going forward.

Figure 5 presents our forecast under the P1.a parametrization. We simulate the model 1,500 times, each draw recording the female representation across all Banks over time. To calculate the expected female representation, $E\left[\gamma_{t}\right]$, we compute the mean across all simulations at each point in time. We also track the ninetieth and ninety-fifth percentiles of the ordered draws at each point in time. In Figure 5, we plot two random paths of $\gamma_{t}$ to illustrate the level of variation that can occur when the number of seats is so small.

Table 7 presents the results on representation in 2027 and on the time it would take to achieve equal representation of men and women. Figure 6 presents the average representation over time under the parametrizations P1.a and P1.b. In our baseline P1.a parametrization, we find that in ten years, i.e., by 2027 , female representation is expected to reach about 36.3 percent. An equal representation of females and males under these parameters would occur thirty-one years out from 2017. ${ }^{24}$ The faster growth in $\pi$ in the P1.b parametrization translates into a representation of 44.4 percent in 2027 and equal representation being reached in only thirteen years. The graph also showcases the

\footnotetext{
${ }^{24}$ We also construct a counterfactual parametrization to evaluate the recommended change to allowing two-term tenures for all directors. We use all rates as in the baseline case and the actual hiring model that has been traditionally used for each bank. Although we expect the speed of refreshment to be slower, we find that the change in hiring model has negligible effects on the evolution of representation, and the two paths of representation coincide almost perfectly.
} 
Figure 6 Representation Projections

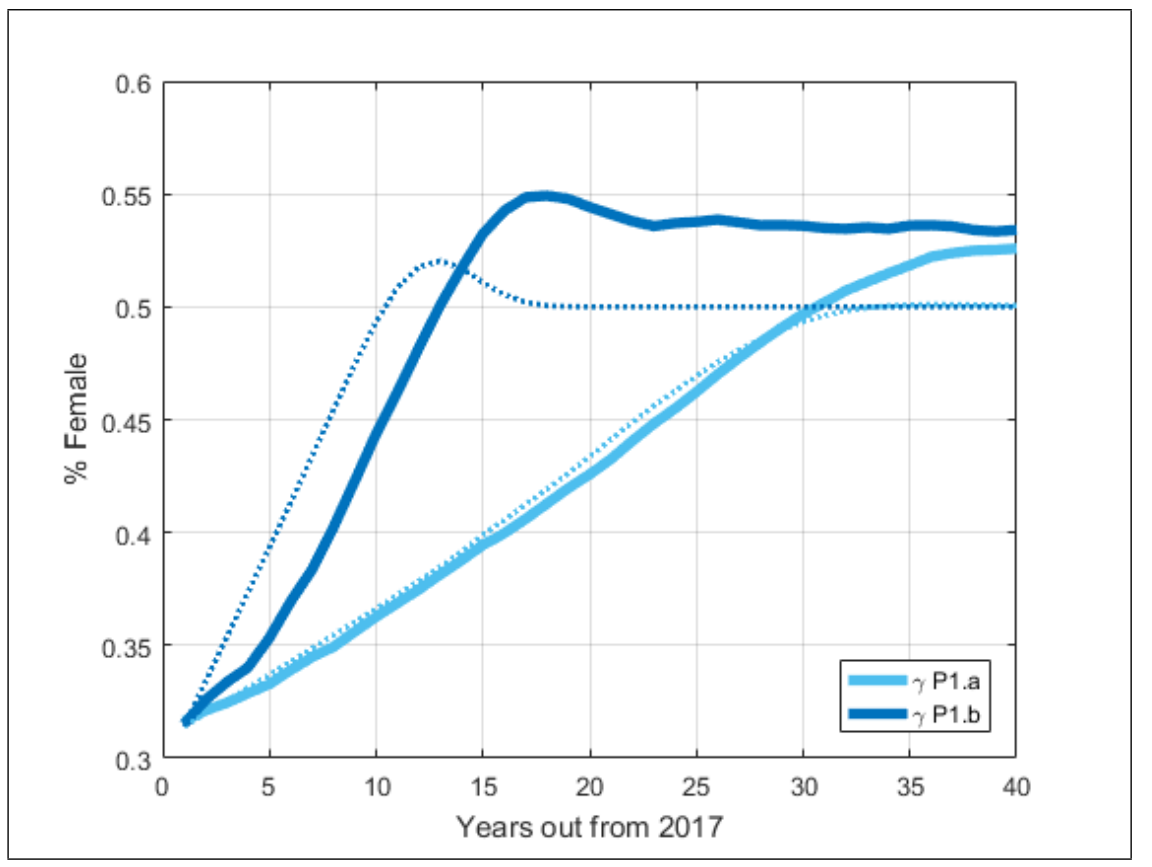

Note: Projections under P1. Dashed line of corresponding color represents the path for the hiring rate $\pi$ used in the projections.

effect on long-term representation of the slightly larger $\Delta$ in the P1.b case: it implies almost 4 percentage points higher representation for females.

\section{HIRING BEYOND THE CEO}

In this section, we discuss how expanding the pool of candidates from where directors are hired might affect female representation. This exercise is motivated by the recommendation a 2011 GAO report that boards tap executives below the CEO level as a way to consider more diverse candidates. Moreover, in a recent town hall meeting with Fed employees, President Esther George, from the Kansas City Fed, and President Loretta Mester, from the Cleveland Fed, mentioned that their 
Table 8 Distribution of Fed Directors across Managerial Categories

\begin{tabular}{|c|c|c|c|c|c|c|}
\hline & \multicolumn{3}{|c|}{$1990-2017$} & \multicolumn{3}{|c|}{$2008-17$} \\
\hline & $\begin{array}{l}\% \text { of all } \\
\text { directors }\end{array}$ & $\begin{array}{l}\% \text { directors } \\
\text { who are } \\
\text { female }(\gamma)\end{array}$ & $\begin{array}{c}\% \text { of } \\
\text { females } \\
\text { with title }\end{array}$ & $\begin{array}{l}\% \text { of all } \\
\text { directors }\end{array}$ & $\begin{array}{l}\% \text { directors } \\
\text { who are } \\
\text { female }(\gamma)\end{array}$ & $\begin{array}{c}\% \text { of } \\
\text { females } \\
\text { with title }\end{array}$ \\
\hline E1 & 73.1 & 13.9 & 57.1 & 82.9 & 19.2 & 71.1 \\
\hline E2 & 6.4 & 41.4 & 12.7 & 7.6 & 51.2 & 13.1 \\
\hline $\mathrm{NE}$ & 20.5 & 32.6 & 30.1 & 9.5 & 33.5 & 15.8 \\
\hline
\end{tabular}

Banks had already been using this strategy in their hiring of directors with that objective. ${ }^{25}$

To evaluate the potential impact of this policy change, we use title information for directors in our sample to compile the gender composition among three different "hiring pools":

- "Tier 1" executive positions (denoted as E1), which includes mainly board chairs and/or CEOs,

- "Tier 2" executives (denoted E2), which include vice presidents, chief financial officers, and chief operating officers, and

- nonexecutives (denoted NE), which primarily include university deans, provosts, professors, and law firm partners.

Our source for director data, the Annual Report of the Federal Reserve System, provides the titles and company information for directors starting in $1990 .{ }^{26}$ We classify titles into the categories E1, E2, and $\mathrm{NE}$, and we feed statistics constructed with this data into our model to construct a counterfactual (P2) that quantifies the potential effects of shifting the composition of the hiring pool away from E1 candidates.

Table 8 summarizes the composition of directors across the three hiring pools. As seen in the first column, during our title sample from 1990 to 2017, on average, 73.1 percent of the directors serving each year (male and female together) have an E1 title, while E2 titles represent 6.4 percent of the directors, and NE positions represent 20.5 percent. The fourth column reports these rates in the last 10 years of the data.

\footnotetext{
${ }^{25}$ We have anecdotal evidence that at the Richmond Fed this strategy has been more heavily used for recruitment of directors at the branches rather than in the main office. We do not look at branch directors in this study.

${ }^{26}$ For the statistics based on this data, we have omitted observations where the title was not recorded $(\mathrm{N}=42)$.
} 


\section{Figure 7 Breakdown of the Population of Directors and the Hires into the Three Hiring Pools}

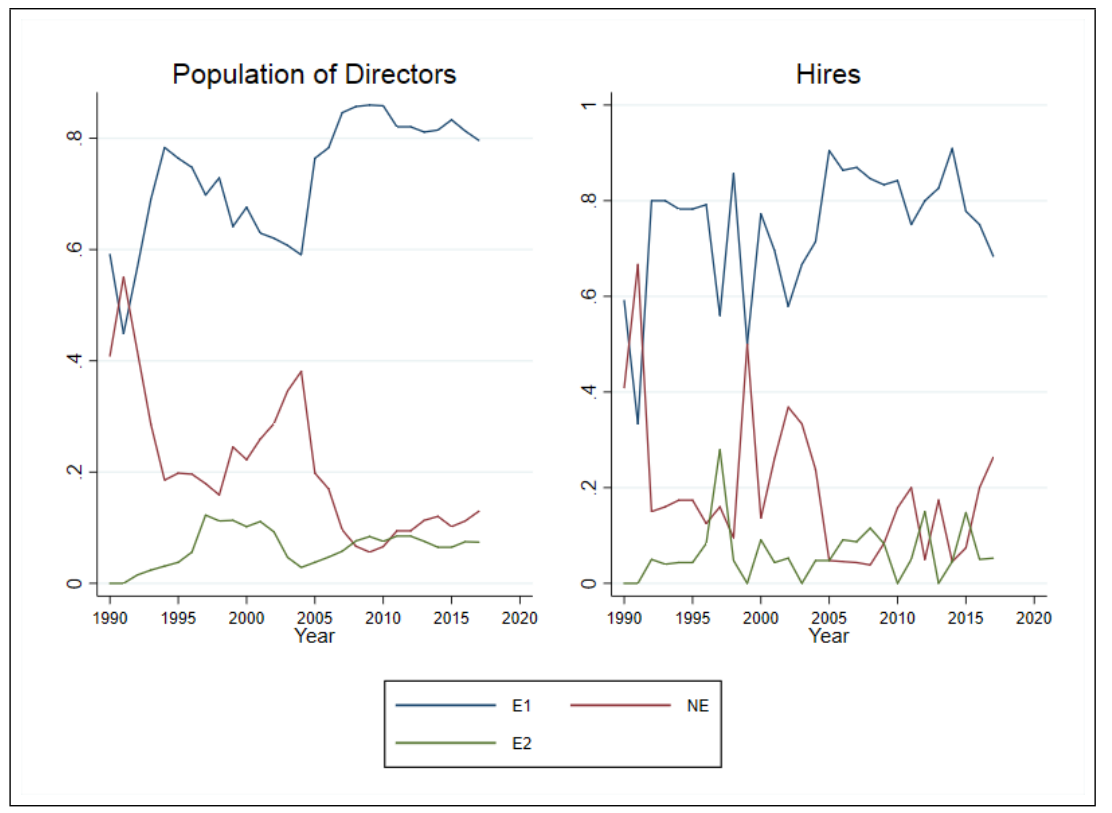

These numbers, as well as the left panel of Figure 7, show that the importance of E1 in the composition of the population of directors has been higher in the last decade. The right panel of Figure 7 presents the evidence regarding hiring rates, showing that director (male and female together) hires from the E1 group have been the highest of the three and their importance has also increased slightly over time.

We use our title data together with our gender indicator to recover female-specific statistics within hiring pools. In what follows, abusing notation slightly, we use the subscript $h \in\{E 1, E 2, N E\}$ to indicate the corresponding statistics for each of the E1, E2, and NE hiring pools. We decompose female representation $(\gamma)$, female hiring rates $(\pi)$, and their growth $(g)$ across the E1, E2, and NE categories.

First, we explore female representation. The second column of Table 8 reports that female representation is much higher outside of the E1 group: 41.4 percent and 32.6 percent for E2 and NE, respectively, compared with only 13.9 percent within E1. For reference, we compare these statistics to the representation of women in two private sector samples. The first sample is Execucomp, composed of the top 1,500 
S\&P firms. ${ }^{27}$ Our own analysis of this data finds that 2.6 percent of CEOs are female, while for non-E1 positions it is 6.8 percent. $^{28}$ The second includes private employers within the financial system with 100 or more employees and federal contractors, which a GAO report uses as comparable to the pool of qualified candidates from where Fed directors are appointed. ${ }^{29}$ Through years $2007-15$, women held 29 percent of executive and senior-level management positions. ${ }^{30}$ The report also indicates that in nonmanagerial positions female representation is 45.1 percent. These two samples, though not a perfect match to the pool from which directors are hired, provide suggestive evidence that it is easier to find females in E2 pools.

The GAO (2017) report also provides some evidence that female representation in executive positions (E1 and E2 combined) has been practically static over the past decade, around 28.6 percent for 2007. On the other hand, as we reported in Table 8, female representation among E1 and E2 directors $\left(\gamma_{E 1}\right.$ and $\left.\gamma_{E 2}\right)$ has increased in the last ten years, while $\gamma_{N E}$ has remained around 33 percent. This suggests that efforts to increase the representation of women directors at the Feds may have been more important within the E1 and E2 pools. This is consistent also with the percent of female directors who have an E1 title being much higher in the last ten years (columns three and six in Table 8).

Next we document the decomposition of the female hiring rate $(\pi)$ by hiring pool. Table 9 (columns two and four) shows the rates for the whole sample period and for the last ten years. For reference, in columns one and three, we report the fraction of all new directors (male and female together) hired from each pool $(\eta)$. We see that $\eta_{E 1}$ has been the highest of the three and has also increased slightly in the last ten years. The evidence indicates that it is not the case that the Feds have shifted their hiring toward the E2 or NE hiring pools,

\footnotetext{
${ }^{27}$ ExecuComp contains information on approximately 2,000 CEOs and 7,000 nonT1 executives per year. EEOC numbers are for financial firms only.

${ }^{28}$ Using data compiled from Standard and Poor's ExecuComp database for 19992006, Gayle et al. (2012) provide similar numbers. They find that only 1.5 percent of the equivalent to our E1 positions are held by women. Representation in positions equivalent to our E2 titles is about 6 percent. The database consists of 2,818 publically tradeable S\&P 1000 firms, which have an average of 18,930 employees.

${ }^{29}$ According to data compiled by the Small Business Administration from the U.S. Census, in 2014, only 106,639 out of 5,825,458 (1.8 percent) firms had 100 or more employees. Available at: https://www.sba.gov/advocacy/firm-size-data.

${ }^{30}$ The statistics for this group come from their required reporting to the EEOC. The EEOC defines the category of executives and senior-level managers as consisiting of individuals who are "in the highest levels of organizations who plan, direct, and formulate policies, and provide overall direction for the development and delivery of products and services."
} 
Table 9 Distribution of Fed Director Hirings across Managerial Categories

\begin{tabular}{|c|c|c|c|c|c|c|}
\hline & \multicolumn{3}{|c|}{ 1990-2017 } & \multicolumn{3}{|c|}{$2008-2017$} \\
\hline & $\begin{array}{c}\% \text { of dir. } \\
\text { hired } \\
(\eta)\end{array}$ & $\begin{array}{l}\% \text { of fem. } \\
\text { within hires } \\
\qquad(\pi)\end{array}$ & $\begin{array}{l}\text { growth } \\
\text { in } \pi \\
\quad(g)\end{array}$ & $\begin{array}{c}\% \text { of dir. } \\
\text { hired } \\
(\eta)\end{array}$ & $\begin{array}{l}\% \text { of fem. } \\
\text { within hires } \\
\qquad(\pi)\end{array}$ & $\begin{array}{l}\text { growth } \\
\text { in } \pi \\
\quad(g)\end{array}$ \\
\hline E1 & 74.6 & 15.4 & 0.007 & 80.2 & 23.2 & 0.015 \\
\hline $\mathrm{E} 2$ & 6.2 & 42.6 & 0.014 & 6.9 & 51.0 & -0.028 \\
\hline $\mathrm{NE}$ & 19.2 & 29.5 & -0.001 & 12.8 & 29.0 & 0.064 \\
\hline Overall & 100 & & 0.0072 & 100 & & 0.0186 \\
\hline
\end{tabular}

which typically have higher female representation. Instead, the Feds have managed over time to attract more females within the E1 hiring pool, which is reflected in the growth in female hires $\left(g_{E 1}\right)$ being twice as large in the last ten years than in the overall sample, as can be seen comparing columns three and six.

Figure 8 provides complementary evidence to Table 9 . It shows the evolution over time in the proportion of female hires $(\pi)$ from each of the three executive categories. The main takeaway is that the proportion of women out of E1 hires (the main source for director hires) has increased steadily over time. We fit a time trend on the three series allowing for a structural break in 2007 to construct a separate parametrization for the last ten years of the sample. The significant break suggests that a recent increase in the female-hiring rate among E1 directors has contributed to the increase in female representation over the last ten years. The trends for E2 and NE are less reliable due to the low numbers of observations per year.

When looking at the breakdown of female hires across hiring pools, we find that the shift toward E1 candidates has actually changed the composition of newer female directors to be fairly similar to that of the males (columns four and six in Table 8 are more similar than columns one and three).

\section{Counterfactual exercise}

To evaluate the effect of changing the relative importance of the three hiring pools, we use our statistical model. Since we only have information about the three pools since 1990, we create a new subperiod, denoted "c," which corresponds to the 1990-2017 year range. In each parametrization we use the growth rates of the female hiring rate by 


\section{Figure 8 Proportion of Female Directors Hired from} Executive Level-Structural Break at 2007

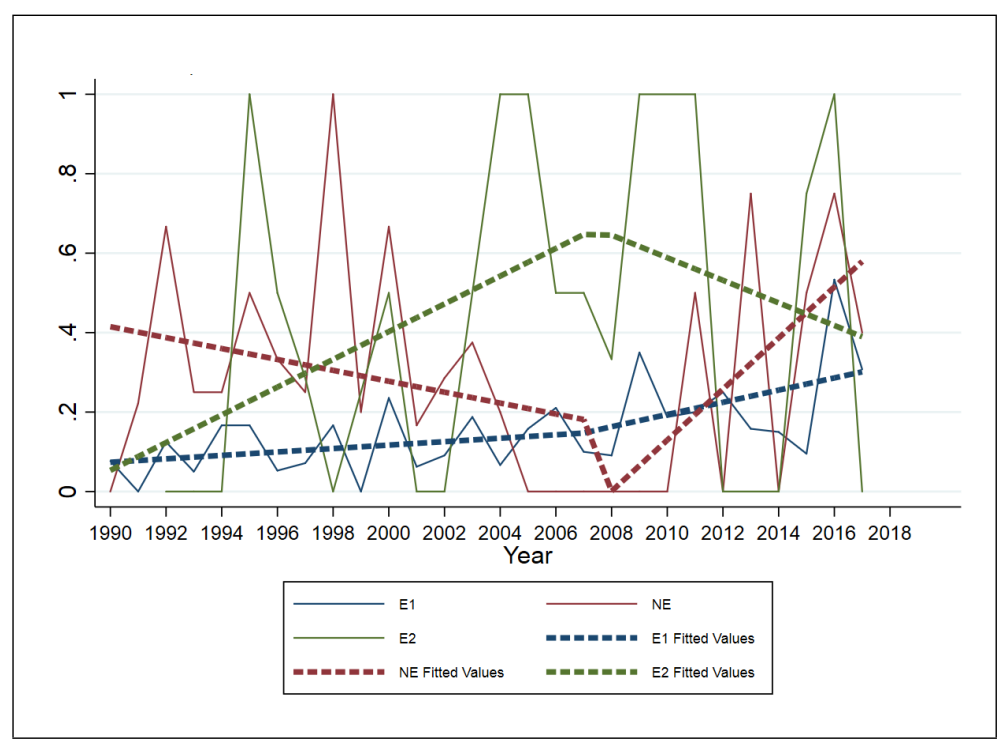

Note: Evolution of female-hiring rate by hiring pool. Fitted values for growth rate $g$ in dashed lines.

hiring sample $\left(g_{E 1}, g_{E 2,} g_{N E}\right)$ that we reported in Table 9 . In our baseline parametrizations, $\mathrm{P} 2 \mathrm{~b}$ and $\mathrm{P} 2 \mathrm{c}$, the overall $g$ corresponds to the weighted-average growth in the proportion of females in hires using the true distribution of hires across pools $\left(\eta_{E 1}, \eta_{E 2}, \eta_{N E}\right) .{ }^{31}$ The initial hiring rate $\pi$ is, as in our baseline parametrization, set to the hiring rate in $2017\left(\pi_{2017}=31.1\right.$ percent females $)$. We compare this benchmark calibration to a counterfactual, denoted P2, of shifting two hires per year per regional Fed from the E1 to the E2 hiring pool. In this counterfactual we take as parametric the growth in the proportion of females across the hiring pools (i.e., we keep $g_{E 1}, g_{E 2}$, and $g_{N E}$ fixed). We construct a counterfactual hiring rate $\pi$ and overall growth $g$ by changing the distribution of hires across the hiring pools (i.e., we com-

${ }^{31}$ This statistic will differ slightly from the $g$ reported in Table 4 because here we construct it by Bank and average over individual Banks. This makes our counterfactuals more intuitive, since we switch two individuals by Bank from one hiring pool to another. We use the $\eta$ rates for the 2008-2017 subsample in all of our projections, since these representation rates are more aligned with the current composition of the boards. 
Table 10 Numerical Results: Female Representation after Ten Years, and Years to Equal Representation

\begin{tabular}{|c|c|c|c|c|c|c|c|c|}
\hline Specification & & $\pi_{2017}$ & $\eta_{E 1}$ & $\eta_{E 2}$ & $\eta_{N E}$ & $g$ & $\widehat{\gamma}_{2027}$ & $\begin{array}{l}\text { Yrs tc } \\
\widehat{\gamma}=.5\end{array}$ \\
\hline P1. Baseline & $\begin{array}{l}\text { b. } 2008-17 \\
\text { c. } 1990-2017\end{array}$ & $\begin{array}{l}31.1 \\
31.1\end{array}$ & $\begin{array}{l}.8 \\
.8\end{array}$ & $\begin{array}{l}.07 \\
.07\end{array}$ & $\begin{array}{l}.13 \\
.13\end{array}$ & $\begin{array}{l}0.0186 \\
0.0072\end{array}$ & $\begin{array}{l}43.9 \\
37.7\end{array}$ & $\begin{array}{l}14 \\
25\end{array}$ \\
\hline $\begin{array}{l}\text { P2. Shifting } 2 \\
\text { hires from } \\
\text { E1 to E2 }\end{array}$ & $\begin{array}{l}\text { b. } 2008-17 \\
\text { c. } 1990-2017\end{array}$ & $\begin{array}{l}34.0 \\
34.0\end{array}$ & $\begin{array}{l}.7 \\
.7\end{array}$ & $\begin{array}{l}.18 \\
.18\end{array}$ & $\begin{array}{l}.12 \\
.12\end{array}$ & $\begin{array}{l}0.0133 \\
0.0078\end{array}$ & $\begin{array}{l}43.8 \\
40.7\end{array}$ & $\begin{array}{l}15 \\
21\end{array}$ \\
\hline \multicolumn{9}{|c|}{$\begin{array}{l}\text { Common parameters: } \\
\gamma_{2017}=31.5\end{array}$} \\
\hline
\end{tabular}

Note: Hats denote values found in each experiment, while no hats denote the value recovered from the data.

pute the implied $\eta_{E 1}, \eta_{E 2}$, and $\eta_{N E}$ of switching two hires from E1 to E2. We multiply these counterfactual weights times $\left[\pi_{E 1}, \pi_{E 2}, \pi_{N E}\right]$ in the year 2017). The resulting counterfactual $\pi$ is 34 percent female hires and a $g$ of 0.0133 when using growth data for the 2008-17 subperiod and of 0.0078 when using growth data for the 1990-2017 period.

The results of this counterfactual are presented in Table 10 and in Figure 9. The results we find depend importantly on whether we use the parameters from the last ten years (our (b) calibration) or those since 1990 (our (c) calibration). In our (b) calibrations, expanding to E2 hiring pools might be good for diversity in background or other dimensions, but it may not be good for female representation: Table 9 shows that even though the growth in female hiring within the E2 pool is higher than within the E1 pool over the period 1990-2017, in the last ten years this trend has reversed. Hence, if female rates within hiring pools represent the true rate of qualified and eligible females, then we should be careful about recommending this policy with the objective of increasing female representation. Of course, it may still be useful to expand outside of the E1 pool, provided it is done with the intention of hiring a female candidate (i.e., if you wish to hire a woman and there are no eligible candidates in the E1 pool).

\section{WHAT IS DRIVING FEMALE HIRING RATES?}

Our empirical analysis and the counterfactual exercises highlight the important role that changes in the hiring rate have (and can) play in female representation on the boards. In this section, we explore a 


\section{Figure 9 Representation Projections: Hiring Counterfactual}

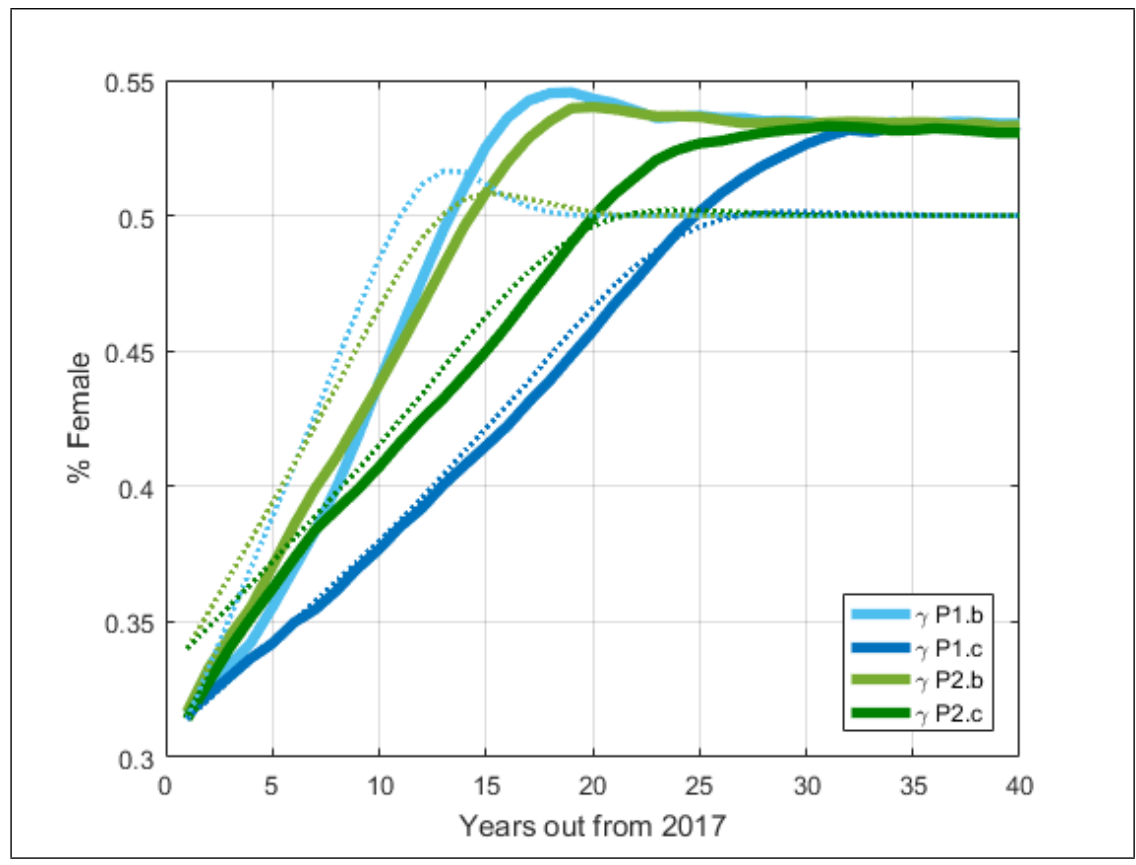

Note: Projections under P1 and P2. Dashed line of corresponding color represents the path for the hiring rate $\pi$ used in the projections.

few possible determinants of the female hiring rate. First, we check the hypothesis that females tend to hire more females by studying the effect of female Fed presidents on the number of females on their own boards. ${ }^{32}$ Second, we explore whether female hiring rates vary with the number of female directors already on the board or depending on whether one of those females just left the board.

\section{Female Fed presidents}

Figure 10 documents the actual series of representation, by Bank, with shaded areas representing the tenure of female presidents. One obvious takeaway from the series is that, despite a general increasing trend for

\footnotetext{
${ }^{32}$ Kunze and Miller (2017), using data from private employers in Norway, find higher promotion rates for females who have female managers.
} 


\section{Figure 10 Representation of Female Board Members over Time}

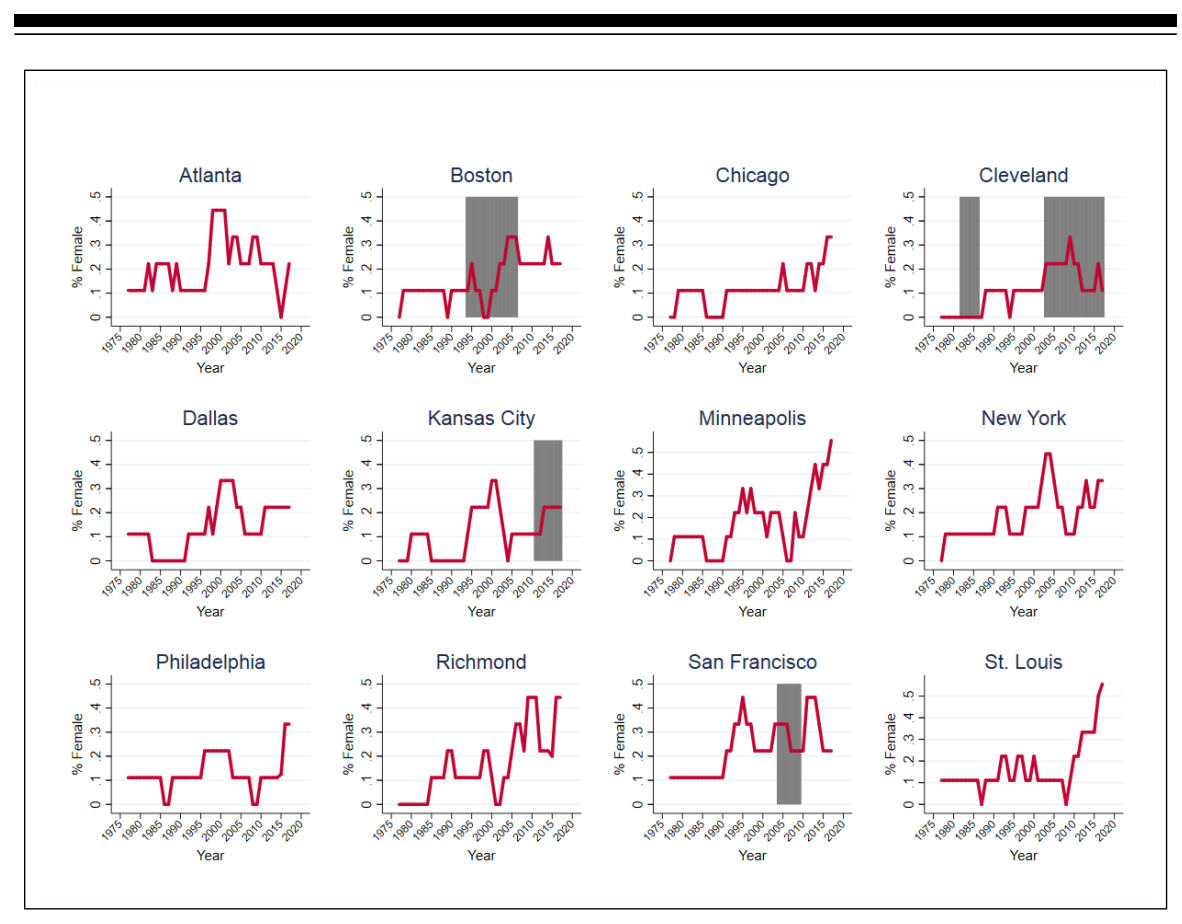

Note: Proportion of female board members over time (red line) and tenure of female Fed presidents (shaded in grey).

all Banks, given the small number of slots by Banks and the tenure limits, representation can change drastically for a given Bank in a few years.

Using panel data (each of the Feds over time), we can check whether female Fed presidents recruit more women for their boards. This could arise if female Fed presidents appointed more women to their boards or if the presence of a female Fed president encouraged other women to accept offers to serve on the board. Because we do not observe offers and acceptance rates for directors, we cannot distinguish between the two explanations.

Tables 11 and 12 list the Fed presidents, the year they were appointed, the number of female directors in the previous year (when their election is likely to have taken place), and the number of women directors hired under each president, along with the proportion of new hires that they represent. 


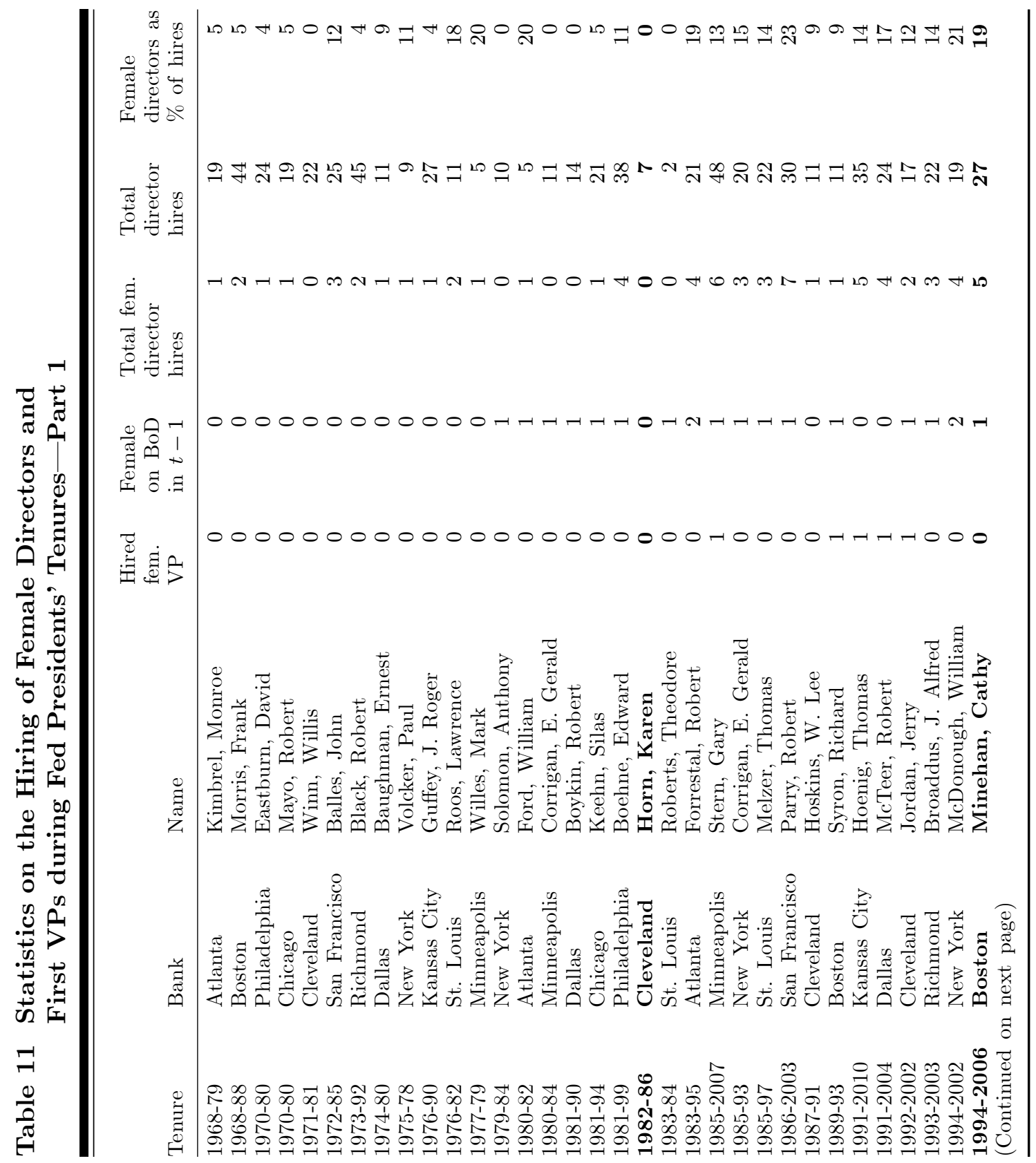




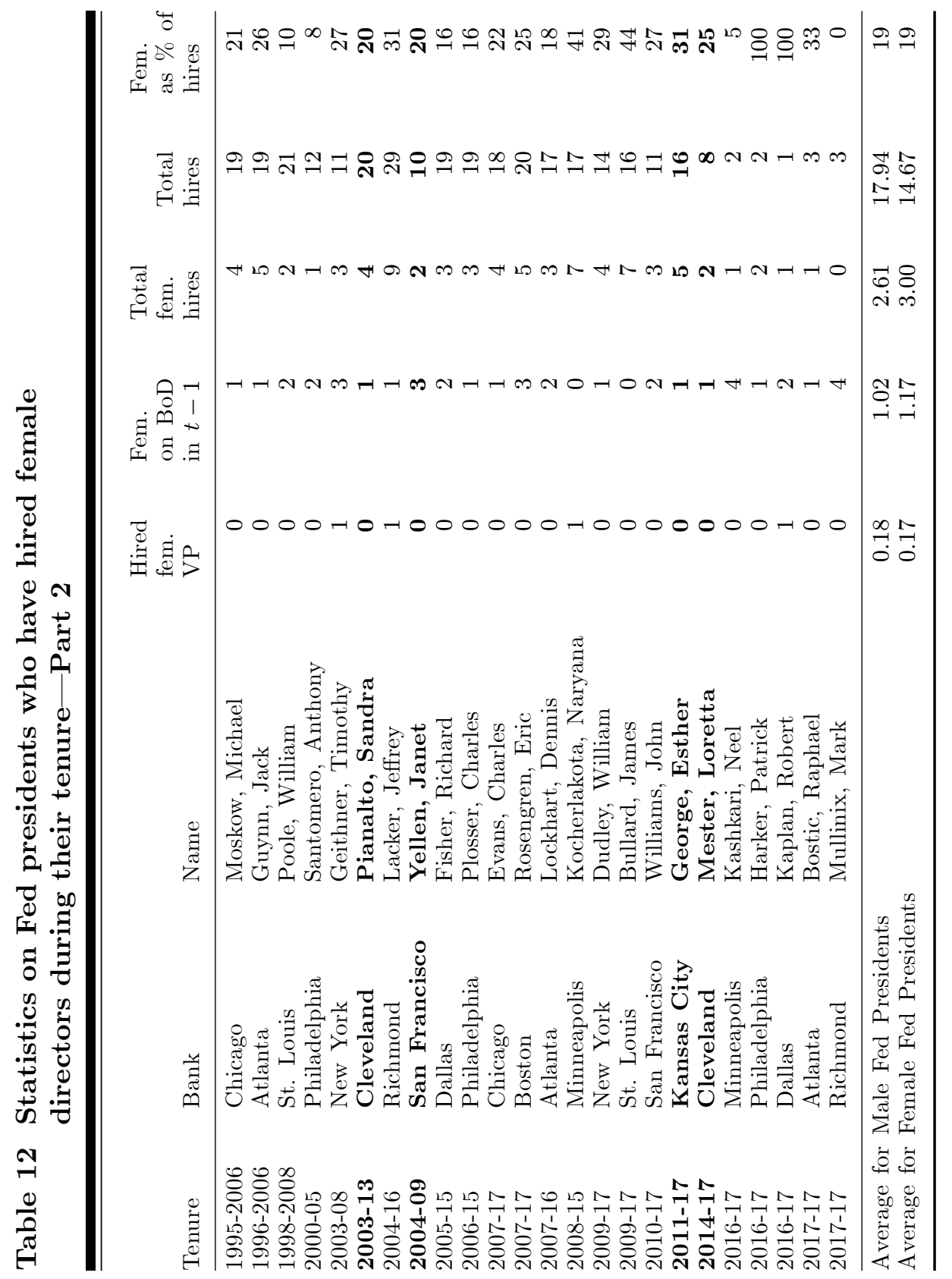


We find that there is no difference between the average proportion of females hired during the tenure of male Fed presidents and that of female presidents, with the proportion equal to 0.19 in both cases. To consider another, related, form of female representation, we also report whether each president ever appointed a woman as first vice president. The first woman appointed to the post of first vice president of one of the regional Feds was Cathy Minehan, at the Boston Fed, in 1991. Minehan was also the second woman ever appointed to the post of president, also at the Boston Fed, in 1994. We find that the proportion of females who appointed a female vice president is 17 percent, while for males it is 18 percent.

These data also beg the question of whether the probability of appointing a female Fed president increases with the number of women on the Bank's board the year before the president started, when the appointment of the female president by the board likely took place. We find that the average number of directors who are female the year before the election of a female Fed president is 1.17. For male presidents, this number is 1.02, a small difference that disappears if we restrict the calculation to the years after the first female president's appointment.

\section{Replacing females and informal quotas}

We find much stronger and intriguing results when we check to see whether hiring practices seem geared toward replacing female directors with other females or toward maintaining a minimum female representation. Table 13 reports the probability of a Fed hiring at least one female in the next year by whether or not a female on that Bank's board left this year (either because she quit or because she completed her maximum tenure). ${ }^{33}$ We find an important and statistically significant (at 5 percent confidence level) difference: Banks that had at least one female leave are twice as likely to hire at least one female (43.6 percent versus 21.5 percent). ${ }^{34}$

To complement this evidence, Table 14 reports again the probability of having at least one female hire for Banks that had a female leave, but now conditioning on the current number of female members on those boards. The evidence in this table suggests that hiring is affected by gender balance concerns. First, the probability of at least one new director being a female when there are no females on the board is

\footnotetext{
${ }^{33}$ To estimate the significance on these conditional means, we run a logit regression. The specification is spelled out in the Appendix.

34 Note that these numbers are consistent with the female hiring rate of 16.6 percent for our sample, since the 43.6 percent of banks that hire females have, most of the time, more than one opening that year.
} 
Table 13 Probability of Hiring a Female in Year $\mathrm{t}+1$, Conditional on Whether at Least One Female Quit in Year $\mathrm{t}$

\begin{tabular}{|c|c|c|}
\hline \multicolumn{3}{|c|}{$\operatorname{Pr}(\text { female hired })_{t+1}$} \\
\hline $\begin{array}{l}\text { Not conditioned } \\
\text { on female quits }\end{array}$ & $\begin{array}{l}\text { One or more } \\
\text { female quit in } t\end{array}$ & $\begin{array}{l}\text { No females } \\
\text { quit in } t\end{array}$ \\
\hline $\begin{array}{l}26.9^{* * *} \\
(2.1)\end{array}$ & $n=110$ & $\begin{array}{l}21.5^{* * *} \\
(2.2)\end{array}$ \\
\hline
\end{tabular}

Note: Data cover entire sample except for the year 1977, when the first five female hires happened. $* * *$ Indicates significance at the 5 percent level.

equal to 31.3 percent, much larger than when there is one woman and she does not leave (16.7 percent). Second, the probability of hiring at least one female is larger when at least one female left in the previous period, for any number of current female directors, but this difference is much larger when the remaining number of females is smaller. For example, in the case where there is only one woman on the board and she leaves, the probability of hiring a woman is 50 percent versus 16.7 percent if only male directors leave; when there are four females on the board, this comparison is 28.6 percent versus 18.2 percent.

To summarize the evidence on the willingness of boards to replace female directors, we can calculate the female hiring rate for Bank-year combinations in which a female left the board: 23 percent of new hires are women. In contrast, the rate is 12 percent when no females left. ${ }^{35}$

It seems reasonable to hypothesize that when the Feds are in search of a "female replacement," as suggested by these data, they might be more likely to consider hiring outside of their usual hiring pool of E1. We can tie the evidence we collected on titles for our P2 counterfactual to check this hypothesis. We check the distribution across hiring pools of female hires at $t+1$ when the only female on the BoD left at $t$. There are nineteen such events in our 1990-2017 sample containing title information. We know from Table 14 that, in the full sample, 50 percent of the Feds looking to hire following such an event bring at least one female onto their board. The percentage of these female hires coming from each hiring pool is reported in Table 15, together with the corresponding composition of female hires for the whole 1990-2017 sample. The numbers should be taken with caution due to the small

${ }^{35}$ This pattern underlies the unconditional female hiring rate of 16.6 percent reported in Table 4. 
Table 14 Probability of Hiring a Female in Year $t+1$ by Number of Females on the Board in Year $t$, Conditional on Whether at Least One Female Quit in Year $\mathrm{t}$

\begin{tabular}{|c|c|c|c|c|c|c|}
\hline \multirow{3}{*}{$\begin{array}{l}\text { Number of } \\
\text { females in } t\end{array}$} & \multicolumn{6}{|c|}{$\operatorname{Pr}(\text { female hired })_{t+1}$} \\
\hline & \multicolumn{2}{|c|}{$\begin{array}{l}\text { Not conditioned } \\
\text { on females leaving }\end{array}$} & \multicolumn{2}{|c|}{$\begin{array}{l}\text { One or more } \\
\text { females leave in } t\end{array}$} & \multicolumn{2}{|c|}{$\begin{array}{l}\text { No females } \\
\text { leave in } t\end{array}$} \\
\hline & $\begin{array}{l}31.3^{* * *} \\
(5.7)\end{array}$ & $n=67$ & $n / a$ & & $\begin{array}{l}31.3^{* * *} \\
(5.1)\end{array}$ & $n=67$ \\
\hline 1 & $\begin{array}{l}22.6^{* * *} \\
(2.9)\end{array}$ & $n=212$ & $\begin{array}{l}50.0^{* * *} \\
(8.1)\end{array}$ & $n=38$ & $\begin{array}{l}16.7^{* * *} \\
(2.8)\end{array}$ & $n=174$ \\
\hline 2 & $\begin{array}{l}31.0^{* * *} \\
(4.3)\end{array}$ & $n=113$ & $\begin{array}{l}42.9^{* * *} \\
(7.6)\end{array}$ & $n=42$ & $\begin{array}{l}23.9^{* * *} \\
(5.1)\end{array}$ & $n=71$ \\
\hline 3 & $\begin{array}{l}34.3^{* * *} \\
(8.0)\end{array}$ & $n=35$ & $\begin{array}{l}39.1^{* * *} \\
(10.2)\end{array}$ & $n=23$ & $\begin{array}{l}25.0^{* *} \\
(12.5)\end{array}$ & $n=12$ \\
\hline 4 & $\begin{array}{l}22.2^{* *} \\
(9.8)\end{array}$ & $n=18$ & $\begin{array}{l}28.6^{*} \\
(17.1)\end{array}$ & $n=7$ & $\begin{array}{l}18.2 \\
(11.6)\end{array}$ & $n=11$ \\
\hline
\end{tabular}

Note: $* * *$ Indicates significance at the 5 percent level.

number of observations, but they suggest that indeed the E2 pool may be tapped in a targeted way to find females, even more so than the NE pool: while the rate of $\mathrm{E} 1$ hires is almost equal to the unconditional mean, the importance of NE decreases, and the probability of hiring from the E2 pool is 3.1 percentage points larger when the only female director leaves and she is replaced by another female than in a random female hire.

Given current practices, it is not unreasonable to think about hiring from E2 as more of an exception than from the NE pool. If the targeted use of E2 is indeed driving the data, this qualifies our conclusion in the counterfactuals of Section 5: the decrease during the last ten years in the proportion of women hired from E2 that is driving our simulation results could be due to fewer situations (such as having the only female member leave) that merit "exceptions" and not indicative of how likely female hires would be if using the E2 pool regularly. Indeed, twentyfour of the total thirty-eight instances of the only female director leaving happen after 1990.

\section{CONCLUSION}

Female presence on the boards of directors of the Feds has been steadily increasing since the first female director was appointed in 1977. This increase has been due mainly to more female directors being recruited, 
Table 15 Distribution of FRB Directors across E1, E2, and NE Titles (1990-2017)

\begin{tabular}{lcc}
\hline \hline & \\
& \% of females from pool $(\eta)$ & $\begin{array}{c}\text { \% of female hires from pool } \\
\text { after the only female quits }\end{array}$ \\
\hline E1 & 57.1 & 57.9 \\
NE & 12.7 & 15.8 \\
NE & 30.1 & 26.3 \\
\hline
\end{tabular}

since, in fact, quitting rates for female and male directors are very similar. Among the boards of directors of the Feds, because complete refreshment happens in at most seven years due to maximum tenure rules, seven years after a change in hiring policies, the expected female representation would be equal to the prevailing female hiring rate, regardless of quitting rates. This means that drastic changes to the hiring rate would be very effective in increasing female representation in less than a decade. Despite the low female presence in executive positions, which sometimes is blamed for the low number of women serving on the boards of the Feds, we find that in cases when female representation is at risk of decreasing significantly, the Feds implement hiring strategies that double the odds of hiring a female director. Though these strategies may not be sustainable for each and every hire, learning about the particular efforts implemented in these instances could be useful in increasing female hires.

Using a statistical model of hiring for boards of directors, we evaluate the effect of a change in hiring practices that would shift some of the hiring from CEOs to non-CEO executives, as suggested by a report by the GAO in 2011. Our exercise highlights the importance of recruitment efforts in attracting females. Using data from the last twenty-seven years, we document that directors recruited from lowerranked executive positions have been more likely to be female than those recruited from the very top executive ranks (CEOs). However, we also uncover a reversal in the trends in the last ten years, with the proportion of females increasing for the CEO pool while decreasing for hires from executives in lower ranks. These trends may reflect the effectiveness of recruitment efforts across the two pools (for example, networks of current female directors with other CEOs may being stronger than with non-CEOs). If we expect them to continue as in the last ten years, a recommendation to hire more often from non-CEO positions may not be a very effective way to increase female representation. 
The data presented in this article are limited to public information on the serving directors. We do not know which candidates were approached nor the takeup rates of offers. Such data would likely help us understand better the reasons behind the limited increase in female hires over time, which we conclude is the main driver of the limited representation of females on the boards of directors of the Federal Reserve Banks. 


\section{REFERENCES}

Adams, Renée B., and Daniel Ferreira. 2009. "Women in the Boardroom and their Impact on Governance and Performance." Journal of Financial Economics 94 (November): 291-309.

Ahern, Kenneth R., and Amy K. Dittmar. 2012. "The Changing of the Boards: The Impact on Firm Valuation of Mandated Female Board Representation." Quarterly Journal of Economics 127 (February): 137-97.

Bayer, Amanda, and Cecilia E. Rouse. 2016. "Diversity in the Economics Profession: A New Attack on an Old Problem." Journal of Economic Perspectives 30 (Fall): 221-42.

Bertrand, Marianne, Sandra E. Black, Sissel Jensen, and Adriana Lleras-Muney. 2019. "Breaking the Glass Ceiling? The Effect of Board Quotas on Female Labor Market Outcomes in Norway." Review of Economic Studies 86 (January): 191-239.

Conyers, John, and Elizabeth Warren. 2016. "Letter to Fed Chair Janet Yellen." May 12. Available at https://www.warren.senate.gov/files/documents/2016-512 _Warren-Conyers.pdf.

Deloitte and the Alliance for Board Diversity. 2016. "Missing Pieces Report: the 2016 Board Diversity Census of Women and Minorities on Fortune 500 Boards."

Farrell, Kathleen A., and Philip L. Hersch. 2005. "Additions to Corporate Boards: the Effect of Gender." Journal of Corporate Finance 11 (March): 85-106.

Flabbi, Luca, Mario Macis, Andrea Moro, and Fabiano Schivardi. 2018. "Do Female Executives Make a Difference? The Impact of Female Leadership on Gender Gaps and Firm Performance." Mimeo (May 4).

Gayle, George-Levi, Limor Golan, and Robert A. Miller. 2012. "Gender Differences in Executive Compensation and Job Mobility." Journal of Labor Economics 30 (October): 829-72.

Hamilton, James. 1994. Time Series Analysis. Princeton, N.J.: Princeton University Press.

Haslett, Kiah Lau, and Gaurang Dholakia. 2018. "Little Progress in Recruiting Female CEOs." Banking Exchange, April 20. Available 
at http://m.bankingexchange.com/news-feed/item/7511-littleprogress-in-recruiting-female-ceos.

Jarque, Arantxa, and Sean McCrary. 2017. "Diversity at the Federal Reserve: Professional Background, Education, and Gender of its Policymakers." Mimeo.

Kunze, Astrid, and Amalia R. Miller. 2017. "Women Helping Women? Evidence from Private Sector Data on Workplace Hierarchies." Review of Economics and Statistics 99 (December): 769-75.

Matsa, David A., and Amalia R. Miller. 2013. "A Female Style in Corporate Leadership? Evidence from Quotas." American Economic Journal: Applied Economics 5 (July): 136-69.

McAfee, James. 2004. "Historical Perspectives on Form and Function: The Evolution of the Fed through the Years." Federal Reserve Bank of Minneapolis The Region, December.

Owen, Ann L., and Judit Temesvary. 2018. "The Performance Effects of Gender Diversity on Bank Boards." Journal of Banking and Finance 90 (May): 50-63.

PwC. 2018a. "Board Composition: Key Trends and Developments." Available at https://www.pwc.com/us/en/governance-insightscenter/publications/assets/pwc-board-composition-key-trendsand-developments.pdf.

PwC. 2018b. "PwC's 2018 Annual Corporate Directors Survey." Available at https://www.pwc.es/es/publicaciones/consejos-ybuen-gobierno/pwc-annual-corporate-directors-survey-2018.pdf.

U.S. Government Accountability Office. 2011. "Federal Reserve Bank Governance: Opportunities Exist to Broaden Director Recruitment Efforts and Increase Transparency." Washington, D.C.: U.S. GAO. October 19.

U.S. Government Accountability Office. 2017. "Financial Services Industry: Trends in Management Representation of Minorities and Women and Diversity Practices, 2007-2015." Washington, D.C.: U.S. GAO. November 8.

Vinnicombe, Susan, Val Singh, Ronald J. Burke, Diana Bilimoria, and Morten Huse, eds. 2008. Women on Corporate Boards of Directors: International Research and Practice. Northampton, Mass.: Edward Elgar Publishing, Inc. 


\section{APPENDIX}

\section{Algorithm for the numerical model}

The simulation returns a $(3 \times 3 \times 12) \times T$ matrix. In each period $t$, each column contains the characteristics of the director occupying a seat for each of the three seats, in each class, in each of the twelve Banks, for each period $t=1, \ldots, T$. Within a class and Bank, the order of the seats reflects the three slots (seats with assigned terms within a class), denoted $s \in\{1,2,3\}$. Within a class, directors are identified by characteristics $(s, \tau, f)$ : the slot they are occupying, their total tenure $(\tau \in\{1,2, \ldots 7\})$, and the indicator for their gender, $f \in\{1,0\}$, which takes a value of 1 if they are female. Quit rates in the simulations are contingent on class.

The law of motion for $f$ depends on both the law of motion for $s$ and $\tau$ and their values, as there are differential average quitting rates depending on where the director is in his or her career and depending on their gender. Denoting with $\gamma^{\prime}, s^{\prime}, \tau^{\prime}$, and $f^{\prime}$ the variables for next period,

- Law of motion of $s$ :

$$
s^{\prime}=\left\{\begin{array}{c}
s+1 \text { for } s=1,2 \\
1 \text { for } s=3
\end{array}\right.
$$

- Law of motion of $\tau$ :

$$
\tau^{\prime}=\left\{\begin{array}{l}
\tau+1 \text { for eligible directors } \\
1 \text { for noneligible directors. }
\end{array}\right.
$$

An "eligible" director is one who qualifies for an additional year of service, according to the rules of maximum tenure and the hiring model. To determine eligibility we create an indicator of the "replacement" status of directors:

$$
r= \begin{cases}0 & \text { if } s=1 \\ 3-(s-1) & \text { if } s>1\end{cases}
$$

That means that if a director quits in the second year of their term, then the replacement director enters into slot 3 and is assigned $r=1$ (they can serve an "extra" year). If a director leaves at the end of his or her first year in the term, the replacement enters into a slot 2 and is assigned $r=2$ (the replacement can serve two "extra" years). Directors who begin their tenure in slot 1 have $r=0$ and go by the usual term rules. This variable allows us to write the rule for maximum tenure compactly in the 
code. Let $Y$ be the maximum number of terms allowed by a given hiring model (f.e., $Y=2$ if a Bank is using HM2). For a director to be eligible for an additional year of service, it must be the case that

$$
\tau<3 Y+r
$$

and

$$
3 Y+r<7 .
$$

In our simulations, the gender of the initial set of directors at $t=1$ is determined by current female representation, or $\gamma_{2017}$. These directors randomly inherit a tenure $\tau \in(s, s+3)$, and all are of replacement status $r=0 .{ }^{36}$ An eligible current director faces a quitting rate $q_{s, \tau}$ if $f=1$ and a quitting rate of $q_{s, \tau}+\Delta_{s, \tau}$ if $f=0$. A noneligible director is forced to separate from his or her seat: $q_{s, \tau}=1$. If a director is separated, then he or she is replaced by a female director with probability $\pi$, where this probability grows over time according to

$$
\pi_{2017+t}=\left\{\begin{array}{ll}
\pi_{2017}+g t & \text { if } \gamma_{k}<50 \text { for all } k<t \\
50 & \text { otherwise }
\end{array} ;\right.
$$

where $g$ is the empirical growth rate of $\pi$ corresponding to the time period used for setting the parameters.

The law of motion for $f$ takes the form

$$
\left[\gamma^{\prime}, 1-\gamma^{\prime}\right]=[\gamma, 1-\gamma] \Pi(s, \tau),
$$

where $\Pi(s, \tau)$ is the gender transition matrix:

$$
\Pi(s, \tau)=\left[\begin{array}{ll}
\operatorname{Pr}\left(f^{\prime}=1 \mid s, \tau, 1\right) & \operatorname{Pr}\left(f^{\prime}=0 \mid s, \tau, 1\right) \\
\operatorname{Pr}\left(f^{\prime}=1 \mid s, \tau, 0\right) & \operatorname{Pr}\left(f^{\prime}=0 \mid s, \tau, 0\right)
\end{array}\right] .
$$

These transition probabilities take different forms, according to the laws of motion of $s$ and $\tau$, and the probability of hiring a female, $\pi$. For eligible directors, this matrix can be written as

$\Pi(s, \tau)=\left[\begin{array}{cc}{\left[1-q_{s, \tau}\right]+q_{s, \tau} \pi} & q_{s, \tau}(1-\pi) \\ {\left[q_{s, \tau}+\Delta_{s, \tau}\right] \pi} & \left(q_{s, \tau}+\Delta_{s, \tau}\right)(1-\pi)+\left(1-q_{s, \tau}-\Delta_{s, \tau}\right)\end{array}\right]$.

For noneligible directors, it simplifies to

$$
\Pi(s, \tau)=\left[\begin{array}{cc}
\pi & 1-\pi \\
\pi & 1-\pi
\end{array}\right]
$$

\footnotetext{
${ }^{36}$ We do not use the true tenures in the data because there are several exceptions to the rules of maximum tenures that we are using in the model.
} 


\section{Derivation of long-term female representation without term limits}

In what follows, we derive the expression in equation 1 in Section 3. In this simple model without tenure limits, we drop the dependence of the quitting rates $q$ and $\Delta$ on $s$ and $\tau$, and we assume $\pi$ does not grow over time. Hence the gender transition matrix is independent of $s$ and $\tau$.

The law of motion for gender is equal to:

$$
\left[\gamma^{\prime}, \quad 1-\gamma^{\prime}\right]=[\gamma, 1-\gamma] \Pi .
$$

One period ahead, this gives us the following expressions:

$$
\begin{aligned}
\gamma^{\prime} & =\gamma[(1-q)+q \pi]+(1-\gamma)(q+\Delta) \pi, \\
1-\gamma^{\prime} & =\gamma[q(1-\pi)]+(1-\gamma)[(q+\Delta)(1-\pi)+1-q-\Delta] .
\end{aligned}
$$

Thus, if there is a female in a given seat, i.e. $\gamma=1$, we have

$$
\left[\gamma^{\prime}, \quad 1-\gamma^{\prime}\right]=[(1-q)+q \pi, \quad q(1-\pi)] .
$$

Female representation after $n$ periods is

$$
\left[\gamma_{n}, 1-\gamma_{n}\right]=\left[\gamma_{0}, \quad 1-\gamma_{0}\right] \Pi^{n},
$$

with

$$
\begin{aligned}
\Pi^{n}= & \frac{1}{q+\Delta \pi}\left[\begin{array}{cc}
(q+\Delta) \pi & q(1-\pi) \\
(q+\Delta) \pi & q(1-\pi)
\end{array}\right] \\
& +\frac{(1-q-\Delta \pi)^{n}}{q+\Delta \pi}\left[\begin{array}{cc}
q(1-\pi) & -q(1-\pi) \\
-(q+\Delta) \pi & (q+\Delta) \pi
\end{array}\right],
\end{aligned}
$$

or, expanding the product, we can write this expression as

$$
\Pi^{n}=\frac{1}{q+\Delta \pi} A,
$$

where $A$ represents the following matrix:

$$
\begin{aligned}
& {\left[\begin{array}{cc}
(q+\Delta) \pi+(1-q-\Delta \pi)^{n} q(1-\pi) & q(1-\pi)-(1-q-\Delta \pi)^{n} q(1-\pi) \\
(q+\Delta) \pi-(1-q-\Delta \pi)^{n}(q+\Delta) \pi & q(1-\pi)+(1-q-\Delta \pi)^{n}(q+\Delta) \pi
\end{array}\right] } \\
= & {\left[\begin{array}{cc}
(q \pi+\Delta \pi)+(1-q-\Delta \pi)^{n} q(1-\pi) & q(1-\pi)\left(1-(1-q-\Delta \pi)^{n}\right) \\
(q \pi+\Delta \pi)\left[1-(1-q-\Delta \pi)^{n}\right] & q(1-\pi)+(1-q-\Delta \pi)^{n}(q \pi+\Delta \pi)
\end{array}\right] . }
\end{aligned}
$$

The probability of having a female in a seat after $n$ periods, $\gamma^{n}$, given an initial state of representation $\gamma_{0}$, is given by:

$$
\begin{aligned}
\gamma^{n}= & \frac{1}{q+\Delta \pi}\left\{\gamma_{0}\left[(q+\Delta) \pi+(1-q-\Delta \pi)^{n} q(1-\pi)\right]\right. \\
& \left.+\left(1-\gamma_{0}\right)\left[(q+\Delta) \pi-(1-q-\Delta \pi)^{n}(q+\Delta) \pi\right]\right\} \\
= & (1-q-\Delta \pi)^{n} \gamma_{0}+\left[1-(1-q-\Delta \pi)^{n}\right] \frac{q \pi+\Delta \pi}{q+\Delta \pi}
\end{aligned}
$$


where $\frac{q \pi+\Delta \pi}{q+\Delta \pi}$ is the probability of having a female in a given seat when $n$ is very large. ${ }^{37}$

\section{Quitting rates}

The quitting rates in the table included in Figure 11 were used in all the (a) parametrizations (corresponding to the whole sample). Because we include replacement directors in this table, for any given slot (which determines years left in current term) more than two tenure values are possible. Hence separate quitting rates, according to slot and tenure, and the numbers speak to the effect of tenure separately.

In the model, for tenure and slot combinations where there are no observations for a particular class, we impute the quitting rate as the average quitting rate for that tenure and slot combination across all classes. The imputed rates are displayed here as well for rows with $\omega_{f}=0$.

The quitting rates in Table 16 were used in all the (b) parametrizations (corresponding to data in the last ten years). Because there are fewer observations when we restrict the sample to the last ten years, we exclude from the table the replacement directors. This means that for any given slot (which determines years left in current term) only two tenure values are possible.

\footnotetext{
${ }^{37}$ For a textbook treatment of these transition dynamics, see Hamilton (1994).
} 
Figure 11 Statistics for Quits Used in (a) Parametrizations

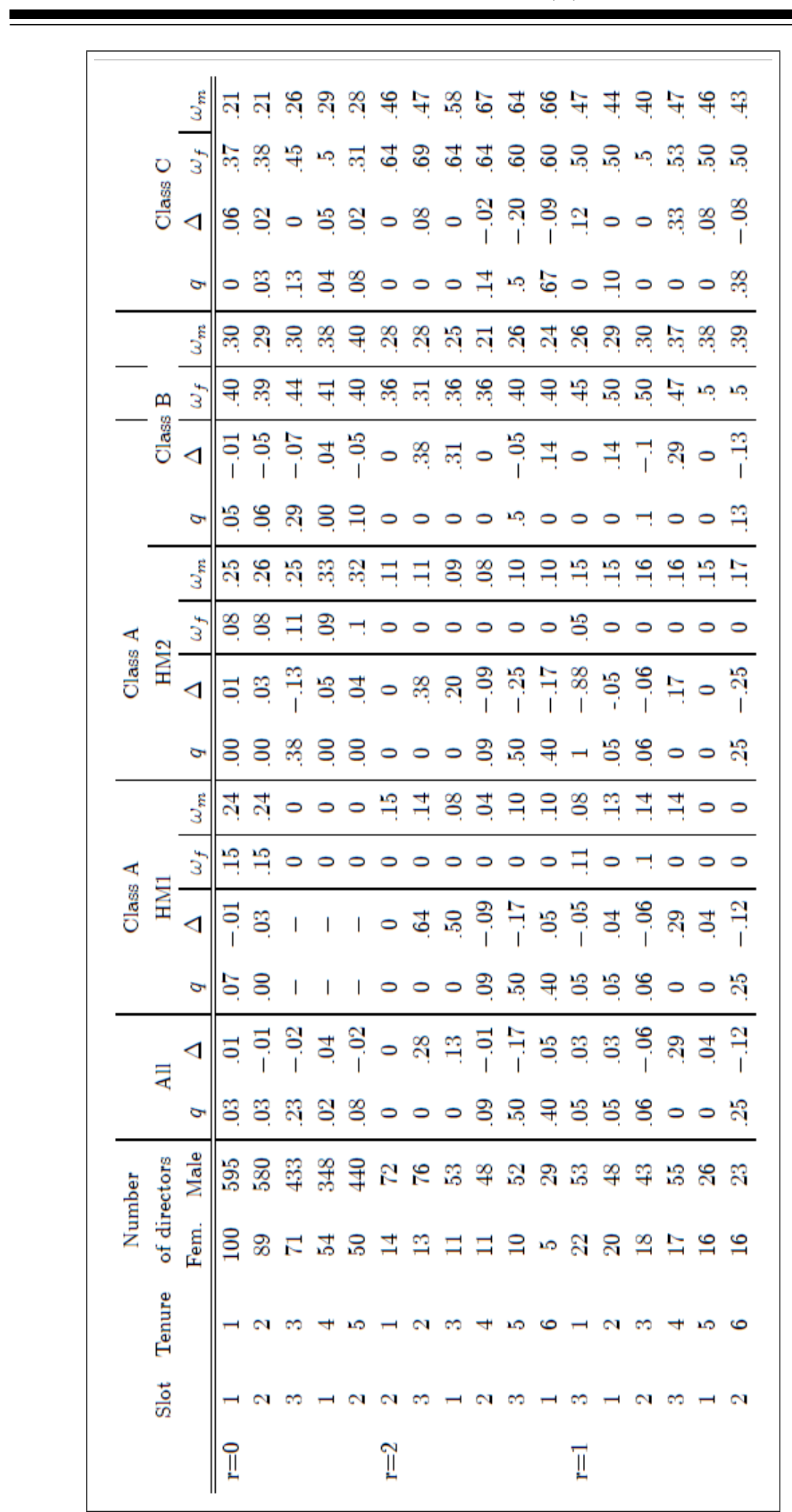

Note: We include replacement directors, which means that for any given slot more than two tenure values are possible. 


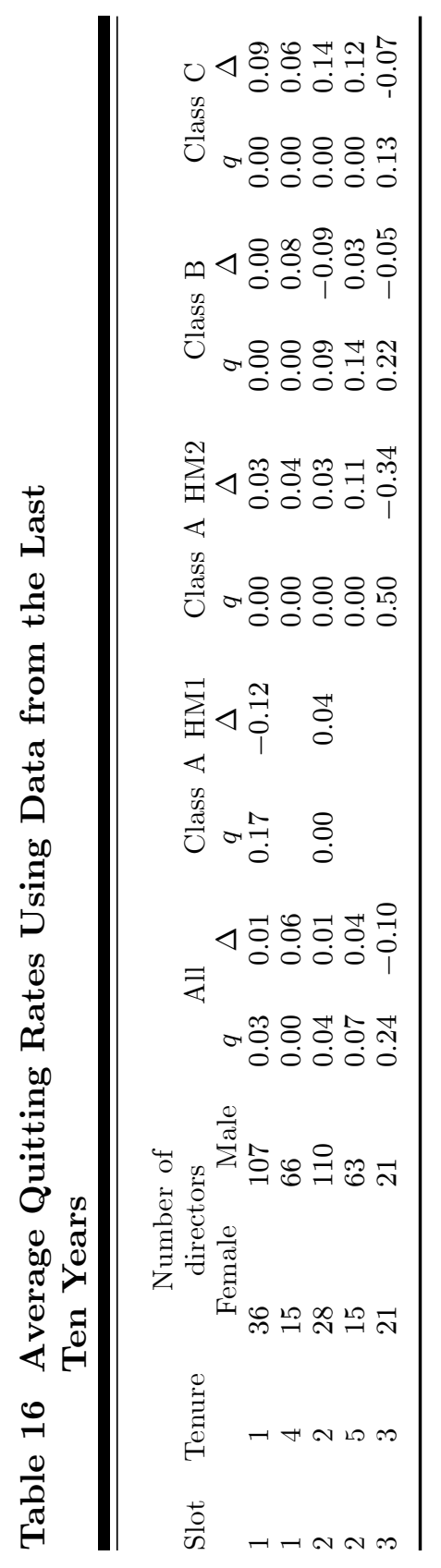




\section{Estimation of conditional hiring rates in Tables 13 and 14}

To estimate the conditional hiring rates in Table 13, we use observations at the year $(t)$ and Bank $(i)$ level for which we observe a hire. These observations always follow a separation in $t-1$, either due to a quit or because of the end of allowed tenure. We construct the variable $f$ hire ti $_{i}$, which takes a value of 1 if at least one female was hired at Bank $i$ in year $t$, and 0 if only males were hired. We also construct the variable $f_{-} q_{u i t_{t-1, i}}$, which takes a value of 1 if at least one female director left Bank $i$ in year $t-1$. We are interested in the marginal effects of having at least one female quit last year from Bank $i^{\prime}$ s board $\left(f_{-}\right.$quit $\left._{t-1, i}=1\right)$ on the probability of hiring a female this year to Bank $i$ 's board $\left(f_{\text {_ }}\right.$ hire $\left.e_{t i}=1\right)$. We run a logit regression with the following functional form:

$$
\operatorname{Pr}\left(f_{-} \text {hire }_{t i j}=1\right)=f\left(\alpha_{0}+\zeta_{i} f_{-} \text {quit }_{t-1, i}+\varepsilon_{t i}\right) .
$$

Using the estimates from this regression, we recover the corresponding marginal effects. Predictive margins for $f_{\text {_q quit }}$ are equal to the difference in the predicted probability of a female hire under the counterfactual of all banks having a female quit and the counterfactual of all Banks not having any female quits. That is, counterfactuals are computed by switching every observation in the sample to $f_{-} q u i t_{t i}=1$ (or $f_{\_} q u i t_{t i}=0$, correspondingly), calculating the predicted probability of hiring a female next year for each observation, and taking the average of these predicted probabilities.

To obtain the predictive margins of whether a female quit by number of females currently on the board (denoted $N_{t i}$ ) on the probability of hiring a female in the next year (margins of $N_{t i} * f_{-} q u i t_{t i}$ as shown in Table 14), we estimate a logit regression of this probability, including on the right-hand side whether a female quit in time $t$, the number of females on the board in time $t$ (denoted $N_{t i}$ ), and the interaction of these two variables:

$\operatorname{Pr}\left(f_{-}\right.$hire $\left._{t i j}=1\right)=f\left(\alpha_{0}+\sum_{i=1}^{12} \alpha_{j} N_{t i}+\zeta_{i} f_{-} q u i t_{t-1, i}+\sum_{i=1}^{12} \beta_{i j} N_{t i} * f_{-} q u i t_{t-1, i}\right)$.

Each observation in the data can be identified by a $\left(N_{t i}, f \_q u i t_{t i}\right)$ pair, and taking the mean hiring probability of observations identified by a particular $\left(N_{t i}, f_{\_} q u i t_{t i}\right)$ is equivalent to computing the predictive margins on the corresponding $N_{t i} * f_{\text {_q }} q u i t_{t i}$ dummy, since there are no more additional variables in our equation that could affect the predicted probabilities for each $\left(N_{t i}, f_{-} q u i t_{t i}\right)$ group. Similarly as before, predictive margins for a given $\left(N, f \_q u i t\right)$ pair are computed by switching 
every observation in the sample to that given value of $\left(N, f \_q u i t\right)$, calculating the predicted probability of hiring a female next year for each observation, and taking the average of these predicted probabilities. The difference between the margins of one or more female quitting and no female quitting is interpreted as the marginal effect of a female quit in $t$, for each possible value of females on the board in $t$.

Further, we can compute predictive margins for only $N_{t i}$ without conditioning on the quit, in other words asking what is the effect of having exactly $N$ females on the board in time $t$. These margins are obtained by estimating the following regression:

$$
\operatorname{Pr}\left(f_{-} \text {hire } e_{t+1, i}\right)=f\left(\alpha_{0}+\sum_{i=1}^{12} \alpha_{j} N_{t i}+\varepsilon_{t i}\right),
$$

and for each level of $N$, switching every observation in the sample to the given $N$, and calculating the average predicted probability. Similarly, this is equivalent to slicing the data by observations with each value of $N$ at $t$ and calculating the average of $f_{-}$hire in $t+1$. 